Portland State University

PDXScholar

12-20-1974

\title{
The Effect of Attending Behavior Training Upon Learning
}

Martha Sue Peden

Portland State University

Follow this and additional works at: https://pdxscholar.library.pdx.edu/open_access_etds

Part of the Communication Commons, and the Educational Assessment, Evaluation, and Research Commons

Let us know how access to this document benefits you.

\section{Recommended Citation}

Peden, Martha Sue, "The Effect of Attending Behavior Training Upon Learning" (1974). Dissertations and Theses. Paper 2122.

https://doi.org/10.15760/etd. 2120

This Thesis is brought to you for free and open access. It has been accepted for inclusion in Dissertations and Theses by an authorized administrator of PDXScholar. Please contact us if we can make this document more accessible: pdxscholar@pdx.edu. 
AN ABSTRACT OF THE THESIS OF Martha Sue Peden "for the Master of Science in Speech Pathology and Audiology presented Decenber 20, 1974. Title: The Effect of Attending Behavior Training Upor Learning. APPROVED BY MEMBERS OF THE THESIS COMMITTEE:

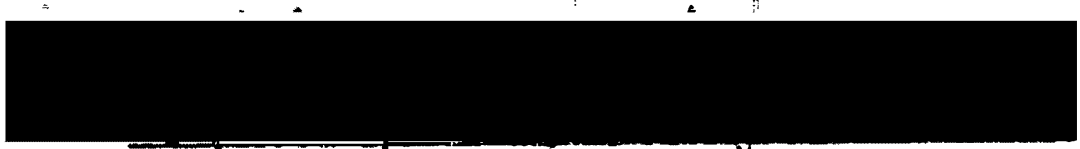
Robert L. Cotsteel, Thairman vi

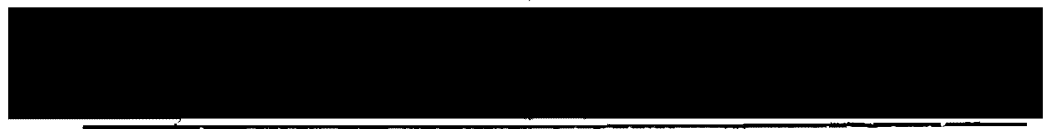

Joan McMahon

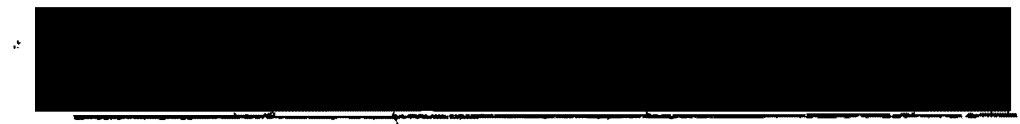

Mary E. Gordon

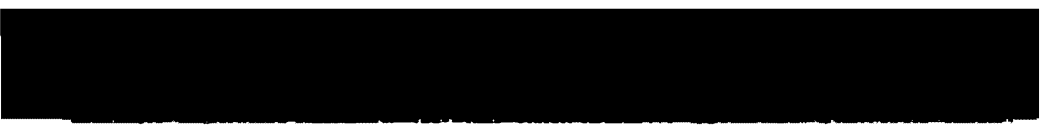

Chad Karr

Various studies have been implemented concerning the physiological and psychological components of attending behavior, particularly in the area of the exceptional child. Little has beendone, however, to develop;specific behavioral definitions of atterding behavior and to incorporate these into treatment-based research programs invoiving normal children attending a regular public scliool.

The purpose of this investiciation was to discover if children from a regular public elementary school who axe deficient in attending behavior skills can be taught these skilis in a short-term behavior modificatión program and to determine if the sills thus learned would 
facilitate learning within the regular classroom setting. A secondary question was asked: Will participation in an attending behavior treatment program change the subjective attitude of the child's teacher in a positive direction?

The resuits demonstrated that attending behavior deficiencies in a normal population were amenable to modification in an individual treatment program. This program ieminated with a lean reinforcement schedule and deliberate interjection of a combination of distracting components into the situation.

The experimental group had significantly higher scores (t of -2:69) than the control group on the easier post-Primer test; there was no significant difference between the two groups on the more difficult post-Primary I test. "The data sugsest, therefore, that: nonattending children can be taught to attend wich will allow them to improve on tasks involving knowledge which may already have been present, but which was not displayed because the child did not attend to variables within the test situation such as directions and instructions. However, the more difficult test would demand perhaps a longer time span between the end of the treatment phase and the post-test to allow the children a period in which to practice and stabilize their newly-learned skills within the classroom learning situation or to acquire additional academic concepts by attending to instructions more effectivelÿ.

There were no significant differences between, the experimental and control groups on subjective rating scales completed on three different occasions by their teachers; in fact, the entire population 
showed an upward movement. This might be explained by maturation, by a change in the child's behavior unrelated to the formal treatment program, or by a more favorable attitude of the teachers toward the children because an outside researcher had concurred in their evaluation of the children as non-attenders and that positive steps were being taken to modify their behavior regardiess of whether the child actually received attending behavior training or not.

There was not a statistically significarit correlation between any of the three subjective rating scales and the post-Primer test scores indicating that (1) possibly. the rating scale was not sensitive enough to reflect subtle differences in attending behavior skills, and/or (2) subtle inter-child differences in in-class attending behavior were not apparent to the-teachers, that is, teacher rating of inclass attending behavior does not necessarily correlate positively with children's performance on a standardized test. 
THE EFFECT OF ATTENDING BEFAVIOR TRAINING UPON LEARNING

by

MARTHA SUE PEDEN

A thesis submitted in partial fulfillment of the requirements for the degree of

MASTER OF SCIENCE IN SPEECH COMMONICATION: EMPHASTS SPEECH PATHOLOGY AND ATDTOLOGY :

Portland State University 1974 
TO THE OFFICE OF GRADUATE STUDIES AND RESEARCH:

The members of the Committee approve the thesis of Martha Sue Peden presented December 20,'1974.

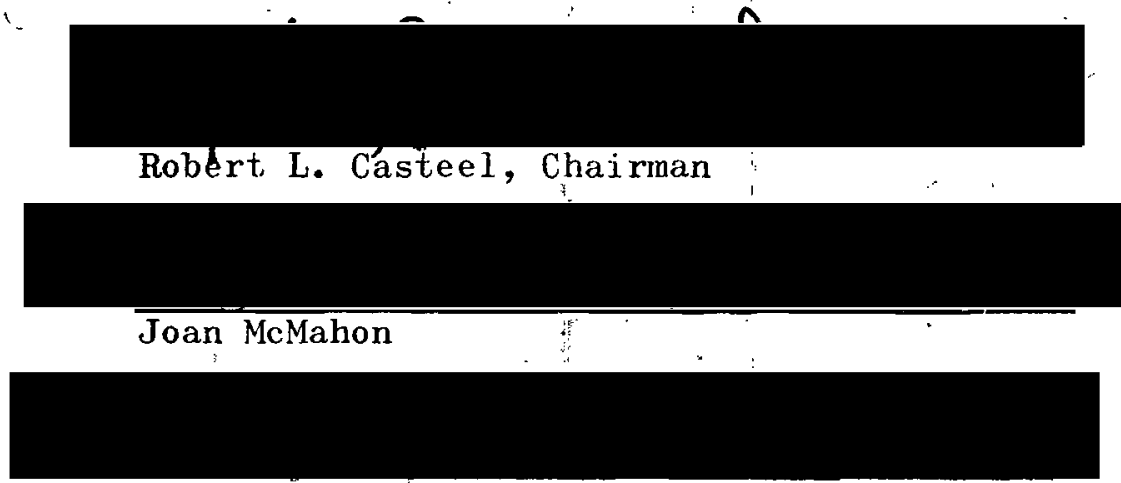

Mary E. Gordon

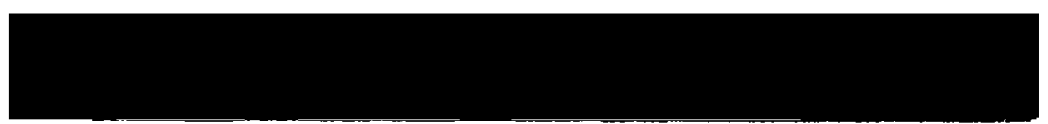

Chad Karr

APPROVED:

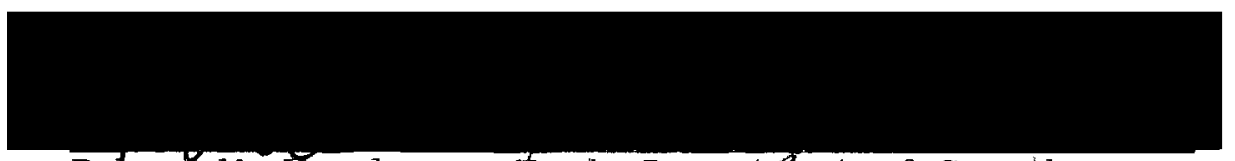

Ropertw. Vogelsang, /fead, Departofent of Speech

நavid T. Clark, Dean of Graduate Studies and Research

December 20,1974 
DEDICATION

To my father and mother, my first teachers. 


\section{ACKNOWLEDGMENTS}

A major original research project, such as a Master's thesis, is primarily the result of an incredible amount of time and effort on the part of the author; however, there are also many who contribute substantially during all stages of planning, implémentation, and data analysis. I would like to express my gratitude, therefore, to:

Dr. Robert L. Castee1, my graduate advisor and thesis director, who really cared enougl to offer his time (often at odd and inconvenient hours for him), suggestions, personal encouragement, and enough freedom so that I could follow my own convictions as to the direction of this research.

Dr. Chad Karr who provided initial design suggestions and was invaluable in the analysis of results.

Joan Melahon who provided the initial design suggestion, and together spent extra time reading the text and providing editorial comments during the writing stages of this thesis.

Dr. Dean Clarkson, and his assistant, Dan Detlefsen, who directed computer analysis of data, and also provided substantial assistance in final data analysis.

The twerty first-grade children from Grout Elemëntary School, Portiand, Orogon, who were the subjects for the study; their teachers, Dianna Lanlon, Mary Hays, and Edna Hawley, and their principal, 
Mr. Henry W. Mascal, for their unflagging patience, courtesy, and cooperation in the face of daily interruption of normal/school routine. Susan and Pat Leonti for consistent personal support and invaluable assistance during the initial planning and implementation stages. To my family and friends for their support and understanding during this period of graduate study when I was often preoccupied, tense, and just too busy! 
TABLE OF CONTENTS

PAGE

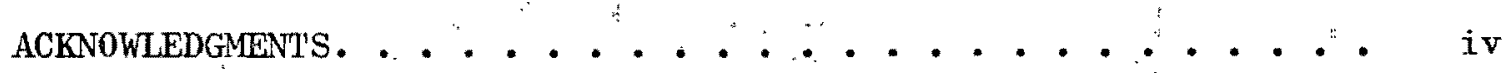

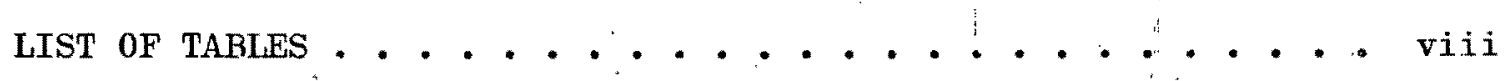
LIST OF FIGURES. . . . . . . . . . . . . . . . . . . . . ix

CHÁPTER

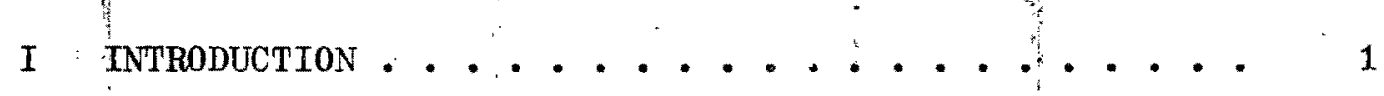

I STATEMENT OF THE PROBLEM . . : . . . . . . . . 3

II DEFINITION OF TERMS . . . . . . . . . . . 4

Attending Behavior..... .......... .4

II REVIEW OF THE LITERATURE . . . . . . . . . . . . 6

I DEFINITION ............... 6

II THEORIES OF ATTENTION . . . . . . . . . . 7

III HISTORY. • • • • • • • • • • • • • 9

IV RESEARCH. . . . . . . . . . . . . . . 9

III PROCEDURES . . . . . . . . . . . . ... 15

I DESIGN . . . . . . . . . ....... 15

Pre-Test Phase ................... 15

Training Phase . . . . . . . ". . . , 15

Post-Test Phase. . . . . ........ 16 
vii

CHAPTER

PAGE

II METHOD. . . . . . . . . . . . . . . . 17

Subjects...................... 17

Clinical Environment .................. 18

Apparatus. . . . . . . . . . 19

Tracking ................. . . 20

Attending Behavior Rating Sheets . . . . . . 20

Data Analysis. . . . . . . . . . . 20

IV RESULTS AND DISCUSSION . . . . . . . . . . . . . 21

I RESULTS. . . . . . . . . . . . . . 21

II DISCUSSION.. . . . . . . . . . . 31

V SUMMARY AND IMPLICATIONS . . . . . . . . . . . 35

I SUMMARY. . . . . . . . . . . 35

II IMPLICATIONS FOR CLINIC, CLASSROOM, AND

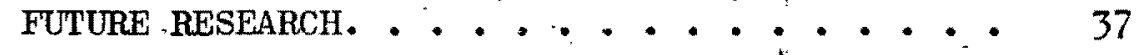

Clinic ............................ 37

classroom. .............................. 37

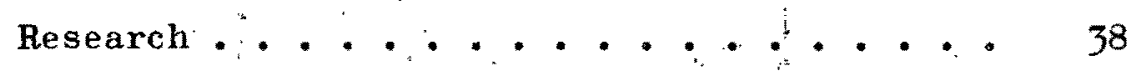

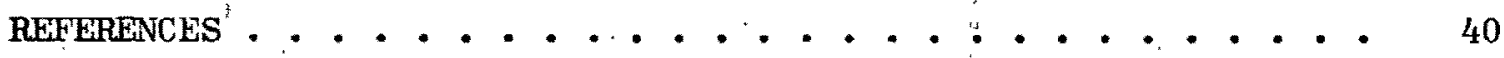

APPENDICES . . . . . . . . . . . . . . . . . . 45

I A HIERARCHAL BRANCHED TREATMENT PROGRAM FOR

MODIFYING ATTENDING BEHAVIOR . . . . . . . . 45

II TRACKING SHEET ..................... 53

III ATTENDING BEHAVTOR RATING SCAJE. - * . • • • . * 55 


\section{LIST OF TABLES}

TABLE

PAGE

I Results of Pre-Training and Post-Training Administrations of Primer and Primary I Tests for Control and Experimental Population . . . . . . . .

II Correlation Coefficients and $t$ Values for Primer

Scores. . . . . . . . . . . . . . . .

III Correlation Coefficients and $t$ Values for Primary I

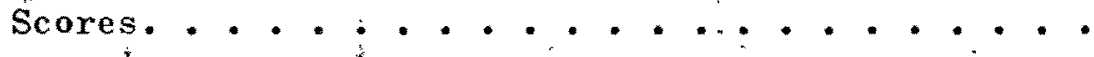

IV Subjective Attending Behavior Rating Scale Showing Mean Scores, Standard Deviations, and Variances .

V. Correlation of Subjective Ratings with Post-Primer

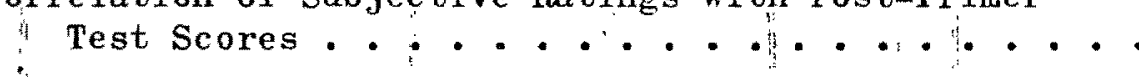




\section{LTST OF FIGURES}

\section{FIGURE}

PAGE

1 Scores for the Experimental Group ( $N=10)$ for the Pre-Training and Post-Training Administrations

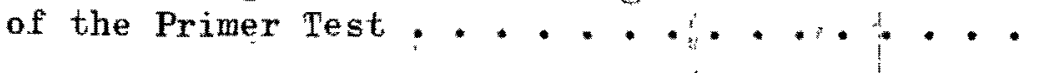

2 Scores for the Control Group $(\mathrm{N}=10)$ for the PreTraining and Post-Training Administrations of the Primer Test. . . . . . . ..........'

3 Scores for the Experimental Group (N=10) for the Pre-Training and Post-Training Administrations of the Primary I Test. ................

4 Scores for the Control Group ( $N=10)$ fox the PreTraining and Post-Training Administrations of

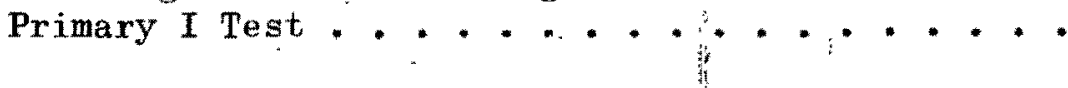

5 Scores for the Experimental Group on Three

Subjective Rating Scales . . . . . . . . . .

6 Scores for the Control Group on Three Subjective

Mating Scales. .... . . . . . . . . . . 


\section{CHAPTER I \\ INTRODUCTION}

Inattention of children has proved to be a major problem in all teaching efforts, spanning a wide range from the regular classroom to the individual treatment or management situation. "Inordinate anounts of teacher training, time, and personal dedication have been expended upon child̆ ren who disrupt learning for themselves and others because they do not exhibit positive, task-oriented attending behaviors.

The child is not a passive receptor of environmental and internal stimuli, but is an active selector, however limited his sapacity to deal with a great number and variety of aviailabie potential stimu1i. The child must sometrow select, therefore", those stimuli which will influence his behavior in a coherent, meaningful way. It is this process of stimulus, selection which Dakon (1966) defined as behavior attention.

Children who lack these selection skills have difficulty in orientation to task-relevant behaviors. Since the educational setting (which may include the physical envjronwent, the task, izternal stimuli, and the teacher or clinician) has little importance as stiuuli for this type of child, he responds indisimimately to them (Marshall and Hegrenes, 1972). Snpiricaliy. his bshaviors appear to be quite random, and the child himself comot state motives for his actions. He does not, for a variety of reascins, possess the control- 
ling mechanism for positive stimulus selection. These random behaviors compete with the clinical set, and in effect, prohibit learning as defined by the teacher or clinician.

When a teacher or clinician is confronted by a child who is academicaily lagging or who is deficient in basic age level concepts, the tendency is to begin immediately presenting the accademic skills or concepts which will bring the child to age or grade level. This type of managent implicitly assumes either that the necessary attending shills are present or that the child can learn even if he cannot attend. Both approaches are fraught with possibilities for failure and disappointment for both teacher and child only minimal learning can take place if the child does not attend (Kent et al., 1972).

If the teacher or clinician does recognize that the child is. not attending to relevant and pertinent stivuli, often a paradign of punishment (nagging the child when he does not attend) or negative reinforceneat (the teacher stops nagging the child when he attends) is employed in order to manipulate these competing behaviors. The teacher or clinician should recognize that any form of adult attention may be reinforcing to some children, so that this type of wanagement may in fact maintain undesirable behaviors, or at best, suppress them only temporarily (Sloane and MacAulay, 1968). Vague, shallow programs lacking specific definitions of behavior, sufficient aćcumulation of baseline data, or criteria for success have also paved the way to failure for wany, chilaren who cannot attend (Magdol, 1973). 
Holland and Schroeder (1960) initially identified and defined attending behavior in terms of a set of operant responses. Furthering this work, Walker and Buckley (1968) found that within ar individual clinical setting, behavior modification conditioning techniques were effective in teaching attending behaviors" In their. study the child had failed to learn attending behaviors within the regular classroom setting. Attending behavior is, thereiore, subject. to methods of behavior modification which have provedisuccessfui for a variety of response. clasise.

Many prograns and strategies have been institutéd for exceptional children who exhibit attending behavior disabilities. Thes include deaf children (Craig and Holland, 1970), mentally retarded children (Kent et al., 1972), emotionally disturbed"children (Lovaes et al., 1966), and "cognitively disorganized"childxen (Marshall and Hegrenes, 1972). To date, no behavior modification researcl has been reported for groups of "average" children: children who do not display characteristics of emotional; motor or sensory inpairment, but who exhibit varieties of attending behavior disabilities which significantly interfere with learning or with normal classroom operation. Research is needed on the learning of children who receive carefully managed training in attending behavior skills prior to presentation of academic skills and concepts. ...

\section{STATEMENT OF THE PEOBIHM}

The present study was designed to deternine whether trainiag in attending pehavior skills alone will positively affect learning as 
measured by a standard instrument.

It is hypothesized that:

1. Children from a regular public elementary school who - are deficient in attending behavior skills can be taught attending skills in a short-term behavior modification program.

2. "Ski11s learned in an individual attending bellavior program will facilitate academic learning within the regular classroom.

3. Participation in an individual attending behavior program will have $a_{4}$ positive effect on the subjective attitude of the teacher toward the child.

\section{DEFINITION OF TERMS}

The following specify operational definitions constructed primarily for this study, and are utilized in the treatment phase and in discussing procedure and resuits:

\section{Attending Behaviox:}

Described by Marshall and Hegrenes (1972) as "an orientation to the clinical set," and rurther defined by themas sitting in one place and attending to visual and auditory cues frompthe clinician or teach-" er. The iollowing are components of attending behavior:

Sitting Behavior. Remaining seated in a chair or other specified place, and inhibiting inappropriate physical movements (fidget-. ing, squirming excessively) for a minimum of tên minutes following a command to do so.

Visual Behavior. Direct eye contact forlten seconds on nine of

tentriais folloving a commana to do so. 
Listening Behavior. The ability to inhibit extraneous or inappropriate vocalization. for a minimum of ten seconds, and attend to instructions or vocalization from the clinician following instructions to do so.

Task-0riented Behavior." The ability to focus upon a task, and to follow instructions regarding the task 90 per cent of the time following a command to do so. 


\section{CHAPTER II}

\section{REVIEW OF THE LITERATURE}

\section{DEFINITION}

Central to any careful thought or examination of a problem is the arrival at a definition of the concept. Various authors have proposed explanations of the concept of attention. Mostofslyy (1970) discussed attending in connection with the orienting response or the "what is it" reflex as distinguished from special defensive reflexes. He described it operationally as "a particular spatial position whichan organism assumes in order to maximize the sensory stimulation which can be expected from that stimulus."

others have defined attention as an instance when an organism engages in an orienting response prior to a response which will, be reinforced (Wyckoff, 1952; Holland, 1960; Reynolds, 1961). Berlyne (1970) termed this type of orienting response as "attention in learning."

Skinner (1938) viewed "attending to" a particular stimulus as a response in its own right which could be acquired through reinforcement. Berlyne (1970) defined attention in terms of intensive aspect;s, i.e., the amount of attention the organism gives to the stimulus rield as a whole, and selective aspects; i.e., the wanner in which the attention is divided among various elements of the stimulus field. He emphasized that attention comes into play after the sense organs bave 
been aroused, and selection is made among stimuli which have already been perceived by the organisin.

Various writers have equated attention with arousal (Hebb, 1955; Malmo, 1957; Berlyne, 1970; Duffy, 1962). Head (1926) introduced the term "vigilance," which is generally. used by psychologists to mean "degree of attentiveness" and has been widely used in human engineering" (Berlyne, 1970).

- Bakan (1966) conceived view of the organism as an active selector, not a passive receptor of impinging stimuli The implication was that attention is not a static dimension, but is dyamic and avallable to modification either from within the organism or from sources out'side of it.

Marshall and Hegrenes (1972)-deined attending behavior as sitting in one" place and attending to visual and auditory cues from the clinician or teacher. "Their reference term is "orientation to the clinical set."

\section{THEORIES OF ATTENTION}

Deutsch and Deutsch (1966) reported a model of attention which included a mechanism that sensed the importance of at stimulus and directed attention to the most important stimuli at any point in time. They found that when the stimuli were significant, the response was relatively simple and widespread and attention was focused upon it; conversely, when the stimuli were not significant, the response was reduced, complex, and localized, and little attention was given to it, 
Moray (1969) concluded that there is not yet enough information to construct a unified theory of attention: He rejected the idea of selection being controlled by a single mechanism, and stated that conscious awareness is probably a glubal property. of the interaction of the activities of many parts of the brain. This view is consistent with current theories of brain function (Millikan and Darley, 1967; Lenneberg, 1968; Smith, 1968; Menyuk, 1971).

Mackworth (1970) stated that the organism is constructed in such a way that it gives naximum attention to the novel, unknown, and potentially dangerous event. The organism must, therefore, repress responses towards familiar, repetitive, and unimportant stimuli. He postulated at least two levels within the organism which deal with impinging stimuli. The first level accepts the stimulus, classifies it as to its jmportance, and represses it or relays it on to higher secondary levels where it is actually registered within the organism's consciousness.

Garanex (1967) pointed out that attention is severely affected by the emotional state of the organism. He maintained that under extreme anxiety, increased distractibility is a common occurrence. According to Broadbent (1958) only certain aspects of the total stimulus situation can initiate complex responses at any one time. Stimuli possessing intensity, biological importance, and novelty are most likely to be selected. He explained extinction of attention in terms of competing stimuli, not competing responses. 


\section{HISTORY}

The problem of attention was of great importance in the early days of expeximental psychology. Binet pointed out as early as 1909 that the degree of attention was of great importance for inteligence subtest results (Frostig.and Maslow, 1973).

Men such as Wundt, Tichener, and Willian James felt that any psychological position should be judged in terms of its treatment of the concept of attention. Subsequent approaches such as Gestalt psychology, peychoanalysis, behaviorism, and $S-R^{1}$ learning theory neglected it (Bnkan, 1966). Later developments suggest that it is once again a core problem reiuforced by important discoveries in the neurophysiology of attention (Horn, 1965; Hernandez-Peon, 1966; Worden, 1966). Recent research into the proulems of attention have been mathematically, and psychologically oriented (Trabasso and Bower, 1968).

\section{RESEARCH}

Moyer and von Haller (1955) concluded that to speak of a mean attention span for normal children is meaningless since their measirements yielued values ranging from several seconds to forty-five minates, although they failed to specify the age range, of the population. They proposed a notion of individual attention spans instead to reflect task and ckild specific values. Redd (1972) found that contingent reinforcement led to increased attention span (defined by hiw as longer periods of continual responding). Expeximental work with congenital returdates by Martin and Fowers (1967) confirmed these findings. State et a!. (1962) found that children's attention spans vary 
greatly. Jsing a population of pre-school children, they increased attention spans by 100 per cent by using contingent praise and treats.

A significant behavioral characteristic of many exceptional children is their fajlure to attend. It is often an awareness of attending deficits which leads the adult to discover their behavioral and learning problems (Magdol, 1975). Straus and Lehtinen (1947) observed that "the brain-damaged organism . . . is abnormally responsive to the stimuli of his environment, responding unselectively, passively, and without conscious intent." Hart and Jones (1968) focused upon the concept of the child as being bombarded by stimuli which normally can be sorted ont so that the child can properly focus upon any one sub-set. The exeeptional child is unable to perform these sorting tasks, and "being distracted is merely the result of the inevitable confusion that overwhelus. . ."

Reward and punishent will infiuence discrimination learning via an attentional mechanism: (Penney, 1967; Witte' and.Grossman, 1971). Penney (196\%) found that groups of retardates operating under a punishment paradigm performed better, i.e., fewer trials to criterion, and exhibited a greater number of orienting responses than a group which received both reward and punishment. Both groups performed better thär a group which received only rewards. Witte and Grossman (1971) concluded that punishment produces more attentive subjects, i.e., more orienting responses and wore correct responses, than re, ward. It was not specified, however, whether the differences were dut to the fact that punishment increased the attentional level of the subjects, or because presentation of the reward served to distract the 
subjects in the reward group. No long-term effects were reported to show that the changes were permanent.

Much of the literature on children's attention to incidental as opposed to focal cues assumes that performance on a task is facilitated by the ability to screen out irrelevant, non-task stimuli (White, 1965; Turnure, 1969). A study by Mondani and Lutke (1969) indicated that under-achievers attend too much to incidental, irrelevant material, and not enough.to the central learning task.

Socially-oriented children glance up from a task primarily in information seeking behavior, rather than in socially-oriented responses (Turnure, 1969). Glances away from the task may represent instances of help-seeking as opposed to inattentiveness, and may indicate optimum moments to teach.

Walker and Buckley (1968) described an individual treatment program for a bright (WISC: 116) male child, aged nine years, six months. The treatment goals were to effect a shaping 'strategy.for attending behavior for this child, and to transfer control to the classroom. In. a previous regular classroom and within an experimental classroom for behaviorally disordered children, he exhibited deviant behaviors (verbally and physically provoking other children, not completing tasks, making loud noises and coments, coercing attention frow the teacher, talking out of turn, and being easily distracted from a given task by ordinary classroom stimuli). Utilizing a fixed reinforcement schedule in forty-minute individual treatment sessions" divided into ten-minute blocks, five days a week, the experimenters "stablished a high rate of positive attending behavior. These skills transferred positively to 
the classroom. Their findings suggest that individual conditioning techniques can be used to acquire efficient reinforcement control over behaviors which are not amenable to modification within the classroom setting. They concluded that these findings have implications for treatment of various behaviors which actively interfere with efficient academic performance among children.

Frostig and Maslow (1973) listed possible causes of poor attending behavior as disturbances in brain function, preoccupation with inner stimuli, or the need to escape from an unpleasant situation. They suggested that the only remedy inmediately available to the classrom teacher is to create an environnent more conducive to learning. Specific suggestions include reducing the amount of irrelevant verbiage, changing vocal expression, tempo and loudness, using attentiongetting devices (switching the iights on and off before giving verbal directions), giving listening cues ("Listen carefully" I am going to dictate an important word."), making individual contact with each child as often as possible, and reinforcing visual stimuli. They stressed the importance of assisting the child who is deficient in auditory figure-ground perception, and thus has difficulty attending consciously to particular auditory stimuli while igroring others. Cautions are given against usjug anything but very mild punishment; a positive approach, in their opinion, is more helpful to the child. Sloane and MacAulay (1968) suggest that. within the regular classroons non-attending is often maintained by what is defined as punishment by the teacher, but is, in fact, reinforcement to the child. They reported at tending belavior training with speech-handicapped chil- 
dren who were also deficient in attending skills. These children did not remain seated and did not attend to the teacher or materials or verbal stimuli presented. They began by reinforcing successive approximations to satisfactory, sitting and attending, and administered punishment in the form of programmed time-out from positive reinforcement. They found that the consequences of good attending behavior appeared to exert more control than did verbal instructions from the clinician:

Gordon (1970) attributed poor attending behavior to children's boredom and frustration within the classroom.

Zimmerman and Zimmerman (1962) removed the social consequences of unproductive classroom behavior (temper tantrums and destructive behaviors) in two emotionally disturbed boys The experimenter initially responded to such behavior by givirg the subject attention while encouraging him to respona appropriately. This approach failed to decrease incidence of tantrum behavior, and the experimenter proceeded to give reinforcement (smiling, chatting, and physical proximity) only after the einission of desired classroom behaviors or close approximations. The students quickly. learned to attend to the teach-. er's questions and to classroom tasks. Birnbrauer, Bijou, and wolf (1965) reserved adult attention for socially acceptable behaviors among eight retarded boys, and increased attention span from a few seconds to twenty minutes at one time. Sloane and Harper (1965) found that even the occurrence of an earthquake in the middie of an experiment failed to disrupt the attending behavior of a retarded subject when that behavior was reinforced. 
Marshall and Hegrenes (1972) suggested strategiés for strengthening attending behavior which were developed from their treatment of twenty-six children who were mentally retarded, emotionally disturbed, and/or organically impaired. They utilized physical restraint when necessary, input amplification delivered via earphones, physical cues, and verbal prompts.

Wagner and Guyer (1971) trained ninety-nine students at the Learning Disabilities Center of the Richmond, Virginia, Public Schools. These children had attending behavior deficits, and had been diagnosed as having either specific learning disabilities or neurological deficits. The experimenters found that conditioning a child's attending. behavior seems to affect general. adjustment positively, decreasing disciplinary problems in: the school.

A review of the literature indicates that previous attempts have not been rade to develop specific behavioral definitions of attending behavior.nor has any research been done to determine the effect of attending behavior training inon the subjective attitude of the classroom teacher toward the child who receives suck training. 
PROCEDURES

\section{DESIGN}

This study was designed in three phases: pre-test, training, and post-test.

\section{Pre-Test Phase}

The Metropolitan Achievement Test Primex (Form F, Grades. $\mathrm{K} .7-1.4$ ) and Primary I (Form F, Grades 1.5-2.4) were administered to twenty children (control and experimental groups) selected for inclusion in the study: This is a standardized achievement test with sections for reading, numbers, listening for sounds (Primer test), and readirg, word analysis, and mathematics (Primary I test). The pre-test was administered to the selected population accoraing to standard test procedure on March 12 and March i4, 1974.

\section{Training Phase}

Length. The training phase of the study was designed to total two hundred minutes of individual attending behavior training per child. This was delivered on a schedule of ten minutes of training per day, five days per week for four weaks. The training phase began April 1, 1974, and conoluded April 29, 1974. The ten chilaren in the experimental group completed the entire four-teek training parse. 
objectives. The overall objectives of the training phase were:

1. To identify specific areas which did not meet criteria as specified in the behavioral definitions of attending behavior components for each child.

2. To modify the specific areas identified until all attending behavior components met criteria.

3. To stabilize attending behavior once criteri'a were met for each component through the introduction of various forms of distraction into the clinical setting. (See Appendix I for complete attending beharior modification program.)

Delineation of the Program. The training phase itself was delineated into three phases: baseline (see "objective one"); wodification (see "0bjective Two"); and stabilization (see "objective Three"). Each child's movement from one phase to the nëext phase was dependent upon his completion of the initial phase; each child provided three days of baseline measurement, including each of the four components o* attending behavior (sitting, Iistening, visual, and task-oriented behavior) to complete the baseline phase and move into the modification phase. Each ebila was required to meet criteria in each of the four component: of attending behavior for three successivedays in order to move from the modification phase inco the stabilization phase. To complete the stabilization phase, each child was required to meet criteria again in each of the four components when faced with the full spectrum of distracting elements as specified, by the attending behavior modification program.

Post-Test Phase

The Merropolitan Achievement, Test Primer (Form H, Grades K.7-1.t) and Primaxy I (Forn II, Grades 1.5-2.4) were administered to the twenty 
children selected for inclusion in the study." The post-test was administered to the entire sample according to standard test procedure on May 28 and May $30,1974$.

\section{METHOD}

Subjects.

The study involved twenty first-grade children selected from the first-grade population at Grout Elementary School, Portland Public Schools, Portland, oregon. The children ranged in age from six years, six months, to eight years and represented an unselected group of first-grade children attending a public elementary school and living in the sane middle-class area of a large urban community. At the outset there was no reason to believe that any systematic difference existed between the children. The subjects were identified as being deficient in attending behavior skills and thus eligible for inclusion in the study on the basis of the following criteria:

1. Significantly (three months) below grade level in at least one academic area, such as reading or wathematics.

2. If instructed to remain seated, did not do so for a. minimum of ten minutes.

3. If instructed to focus upon a task, did not do so for a minimum of thirty seconds.

4." If instructed to look at the teacher, did not make direct eye contact on five of ten trials.

5. If instructed to refrain from extraneous vocalization, did not do so for a winimum of five minutes."

Any child who exhibited behaviors described in the first category listed above, plus any two of the remaining four categories, was eli- 
gible for the study. Iritial selection was made by the child's classroom teacher; verification of the subject's actual in-class attending behavior:was done by the experimenter and the teacher, with the teacher giving the initial stimulus commands and the experimenter tracking the child's responsive behavior:

The twenty subjects selected for inclusion into the study were divided into control and experimental groups by means of a table of random numbers.

\section{Clinical Environment}

For this study the "clinical environment" was operationally defined as the environment in which the various phases of the study were carried out.

Pre-Test Environment. This consisted of a large kindergarten room with two doors and eight windows with western exposure. The room measured 15'x 25', and was lighted by six standard installations of fluorescent lights. In addition to various toys and equipment pertaining to the operation of a public kindergarten classroom, the roon contained seven child-size tables neasuring $2 \frac{1}{2}^{\prime} x^{\prime} 4^{\prime}$, allowing for placement of three children at six tables and two children at one table. The children were seated in random ordex for each test day. Training Phase Environment. For the first week of the training phase the environment consisted of a vice-principal's private office meásuring $15^{\prime} \times 15^{\prime}$ with one door and no windows. The room was lighted with one standard fluorescent light fixtare. The subject ard experimenter sat facing each other across a table. The room also contiained $v$ a desk, three chairs, a bookcase, and fa filing cabinet. 
From the second through the fourth weeks of the tconditioning phase, the environment consisted of a private storage room measuring $10^{\prime} \times 15^{\prime}$. with one door and no windows. The room was lighted with one standard fluorescent light fixture. It contained shelves for equipment storage (primary dry powder paint, paper, clay, typewriters) on all four walls, a clay kiln, a table, and two chairs. The subject and experimenter sat facing each other across the table.

\section{Post-Test Environment. This consisted of a large elementary} school library rooin measuring $25^{\prime} \times 40^{\prime}$ with one door and eight windows with western exposure. The room contained bookshelves on all four walls, a filing cabinet, a desk and chair, four free-standing bookshelves, and eight child-size tables, allowing for placement of three children at four tables and two children at four tables. The children were placed at the tables in random oxdex on the testing. days.

\section{Apparatus}

No apparatus was utilized initially other than tracking sheets, a pencil, and a stopwatch. As soon as criterion was reached in the four components of attending behavior, a Sony reel to reel tape recorder, Model TC104A, was placed on the table in front of the child and pre-recorded distractions were played, When cxiterion was again met, distracting objects were placed on the table. These consisted of a child's book, toy card, colored chips, a pég game, puzzles, candy, and money. 
Tracking.

Tracking of behavior was done by the experimenter on tally sheets, utilizing a check mark if criterion was net or a notation of the number of minutes or seconds of success if criterion was not met. A sample tally sheet is included in Appendix II.

\section{Attending Behavior Rating Sheets}

The three teachers of the children involved in the study completed a subjective attending behavior rating-sheet for each-child enrolied in their classroom. These rating sheets were completed on three separate occasions: March 16, 1974, at the beginning of the study; April 29, 1974, at the conclusion of the conditioning phase; and May 30, 1974, at the conclusion of the study, A sample rating sheet is included in Appendix III.

Data Analysis

The data were analyzed by using multiple regression techniques. 
CHAPTER IV

\section{RESULTS AND DISCUSSION}

\section{RESULTS}

The purpose of this investigation was to determine whether training in attending behavior skills alone will enhance academic learning as measured by a standard instrument.

Two major questions were asked:

1. Can children from a regular public elementary school who are deficient in attending behavior skills be taught these skills in a short-term behavior modification program?

2. Will the attending. skills learned in a short-term behavior modification program facilitate academic learning within the regular classroom setting?

A secondary question was also asked:

Will participation in an individual treatment program have a positive effect on the subjective attitude of the teacher toward the child?

Each child in the experimental group reached the terminal or stabilization stage of the individual Attending Behavior Treatment Program (see Appendix I) by achieving consistent positive attending behavior during the individual treatment phase of the study.

The results of the pretraining and post-training administrations of the Primer and Primary 1 tests for the control and experimental groups are shown in Table I. Both pre- and post-tests were administered to the entire population of twenty childron divided randomly 
into control and experimental groups of ten children each. See Chapter III for specific details of the selection process.'

\section{TABLE $\cdot \mathbf{I}$}

RESULTS OF FRE-TRAINING AND POST-TRAINING ADMINISTRATIONS

" OF PRTMFR AND PRIMARY I TESTS FOR" CONTROL " $A N D$

EXPERIMENI'AL POPITATION

\begin{tabular}{|c|c|c|c|c|}
\hline Test & $\begin{array}{l}\text { Highest } \\
\text { Score }\end{array}$ & $\begin{array}{l}\text { Lowest } \\
\text { Score }\end{array}$ & Mean & $\begin{array}{l}\text { Standard } \\
\text { Deviation }\end{array}$ \\
\hline$\therefore \quad \bar{i}$ & & & & \\
\hline Pré-Primer & 96. & 41 & 83.20 & 12.74 \\
\hline Pre-Primary I & 235 & " & 147.45 & 37.95 \\
\hline Post-Primer & 153 & $\because 55$ & 110.15 & 27.05 \\
\hline Post-Primary I & 202 & $\because 27$ & 155.95 & 37.19 \\
\hline
\end{tabular}

Table II contains correlation coefficients and computed values for the Primer scores for the total population and for the experimental group contrasted with the control group. The control group was coded as +1 and the experimental group as -1 for computer analysis. The computed $t$ value shows the effect of the treatment on the posttreatment Primer scores after statistical adjustment to compensate for the effect of the pre-treatment primer scores. The experimental group did significantly better than the control group; the contrast between the two groups after the statistical adjustment resulted in $a \cdot t$ of -2.69 , which is significant at the 0.05 level.

Table III contains correlation coefficients and computed t values for the Primary I scores for the total population and for the experimental group contrasted with the control group. The control group was. 
coded as +1 and the experimental group as -1 for computer analysis. The computed $t$ value shows the effect of the treatment on the postPrimary I scores after statistical adjustment to compensate for the effect of the pre-Primary I scores. The contrast between the experimental and control groups after this statistical adjustment is -0.29 , which is not statistically significant $(p>.70)$.

TABLE II

CORRELATION COEFFICIENTS AND $t$ VALUES FOR PRTMER SCORES

\begin{tabular}{|c|c|c|c|c|c|c|}
\hline Variable & Mean & $\begin{array}{l}\text { Std. } \\
\text { Dev. }\end{array}$ & $\begin{array}{l}\text { Simple } \\
\text { Correl. }\end{array}$ & $\begin{array}{l}\text { "Paxital } \\
\text { Reg.Coef. }\end{array}$ & $\begin{array}{l}\text { Std.Error } \\
\text { of Regcoef. }\end{array}$ & $\mathrm{t}$ \\
\hline Pre-Primer & 85.20 & 12.74 & 0.48 & 0.68 & 0.40 & 1.71 \\
\hline Post-Primer & 110.15 & 27.05 & - & & & \\
\hline $\begin{array}{l}\text { Contrast between } \\
\text { control/exper. }\end{array}$ & 0.00 & 1.03 & -0.61 & -13.33 & 4.95 & -2.69 \\
\hline
\end{tabular}

TABLE III

CORRELATION COEFFICIENTS AND, $t$ VALUES

FOR PRIMARY I SCORES

\begin{tabular}{|c|c|c|c|c|c|c|c|}
\hline Variable & Mean & $\begin{array}{l}\text { Std. } \\
\text { Dev: }\end{array}$ & $\begin{array}{l}\text { Simple } \\
\text { Correl. }\end{array}$ & $\begin{array}{l}\text { Paxital } \\
\text { Reg.Coef. }\end{array}$ & & $\begin{array}{l}\text { Std.Error } \\
\text { of Reg.Coef. }\end{array}$ & $t$ \\
\hline Pre-Primary I & 147.45 & 37.95 & $0 . l_{t_{i} i_{k}}$ & 0.028 & & 0.20 & 0.14 \\
\hline Poost-Primary I & 155.95 & 37.19 & 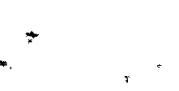 & $=$ & & - & \\
\hline $\begin{array}{l}\text { Contrast between } \\
\text { control/exper. }\end{array}$ & 0.00 & 1.03 & -0.35 & -1.49 & a & 5.11 & -0.29 \\
\hline
\end{tabular}


Figures 1 to 4 graphically illustrate the scores of the control and experimental groups for the pre-, and post-administrations of the Primer and Primary I tests. "Numbers one through tén represunt case numbers for the experimental group; nubbexs eleven through twenty represent case numbers for the control group.

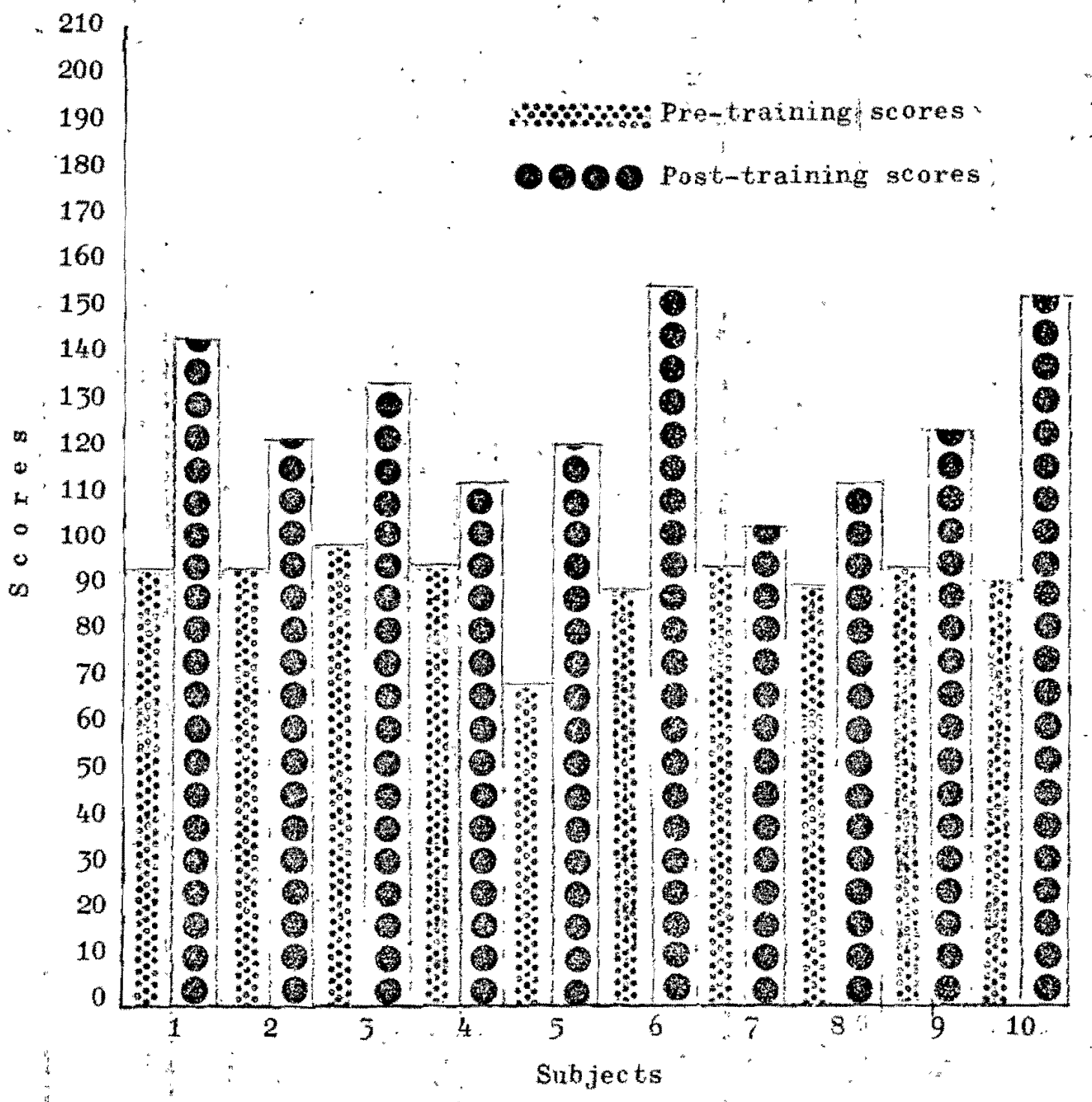

Figure 1. Scores for the experimental group $(N=10)$ for the pre-training and post-training administrations of the primer test. 


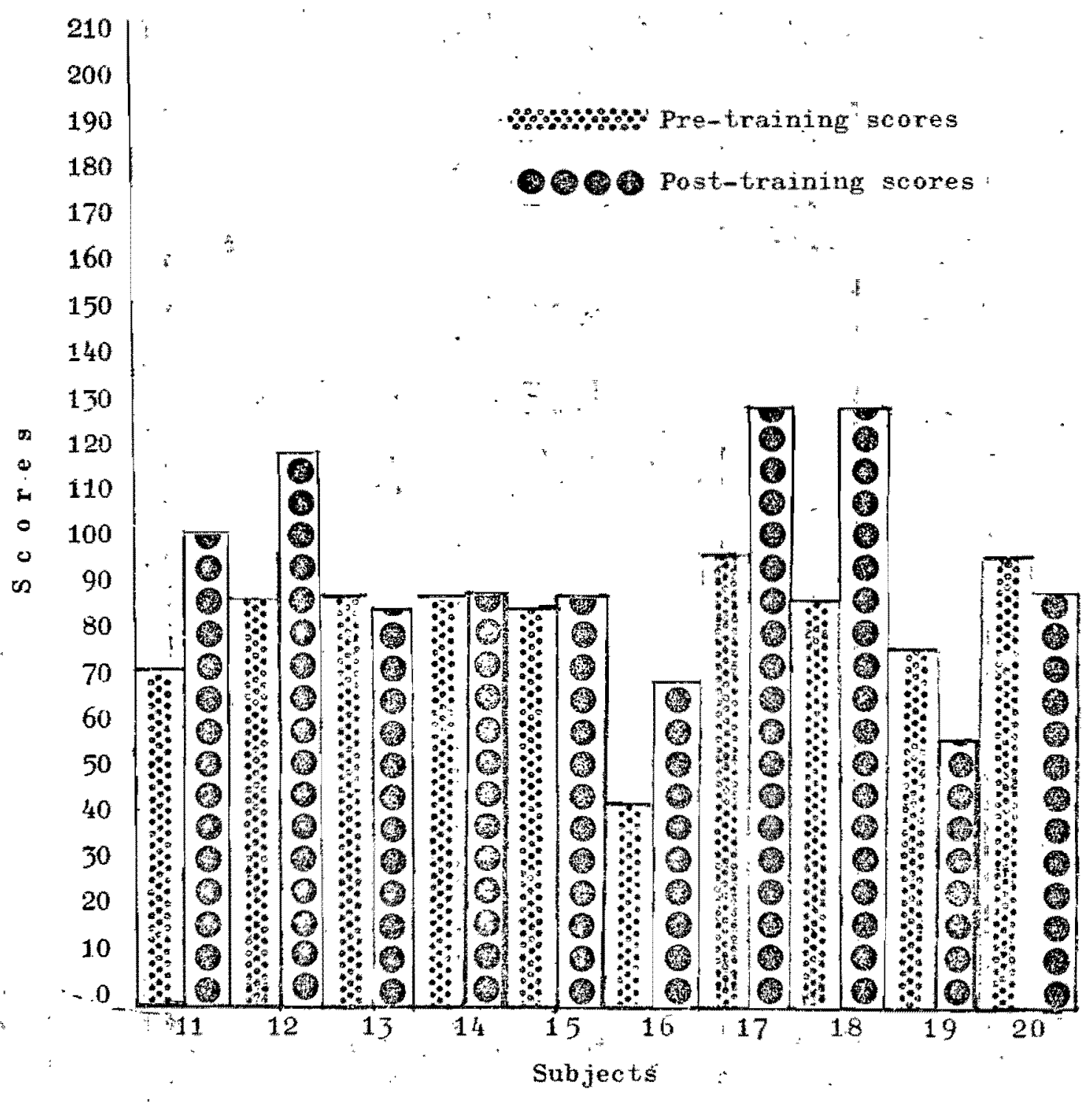

Figure 2. Scores for the control group $(N=10)$ for the pretraining and post-training administrations of the Primer test. 


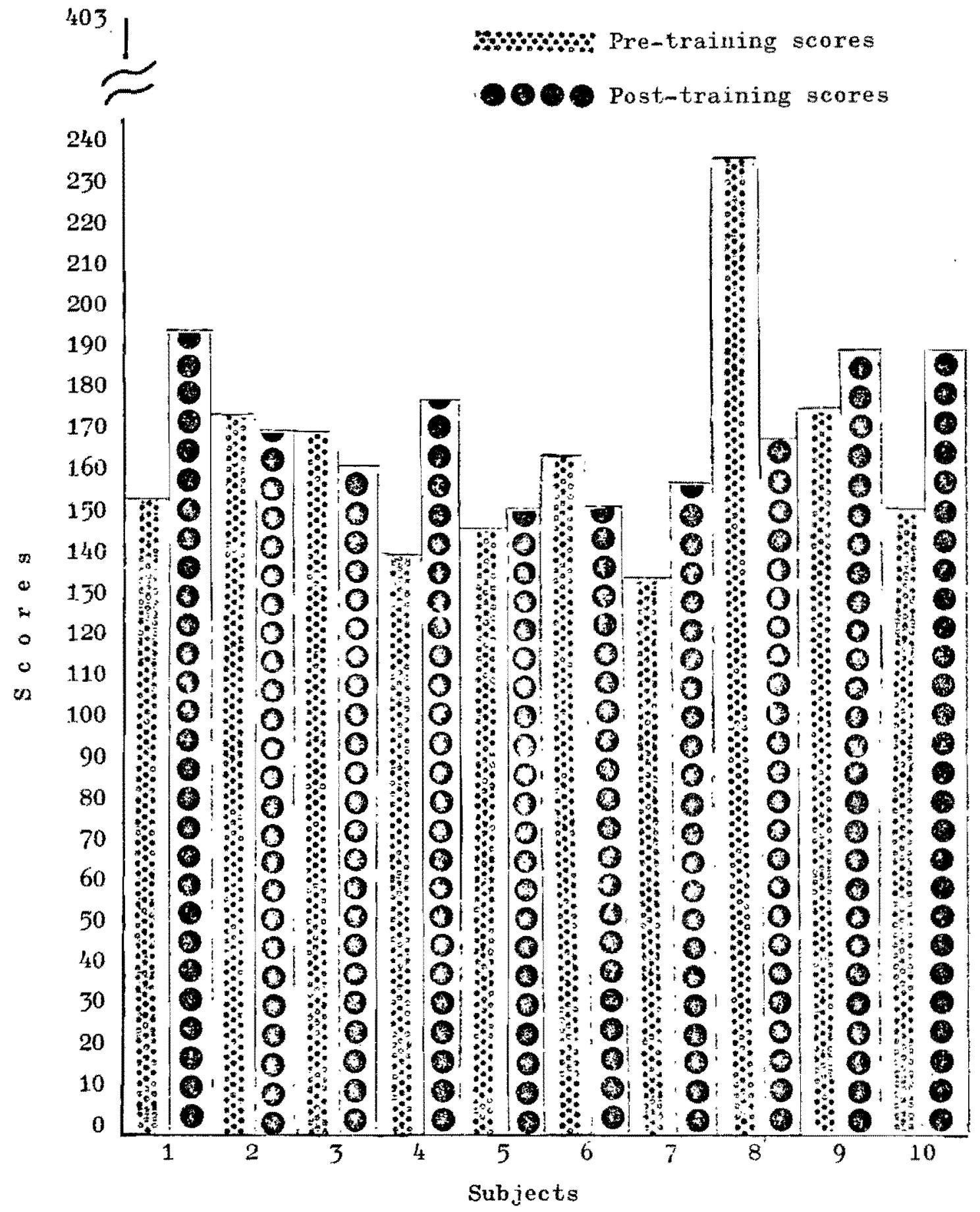

Figure 3. Scores for the experimental group $(N=10)$ for the pre-training and post-training administrations of the Primary I test. 


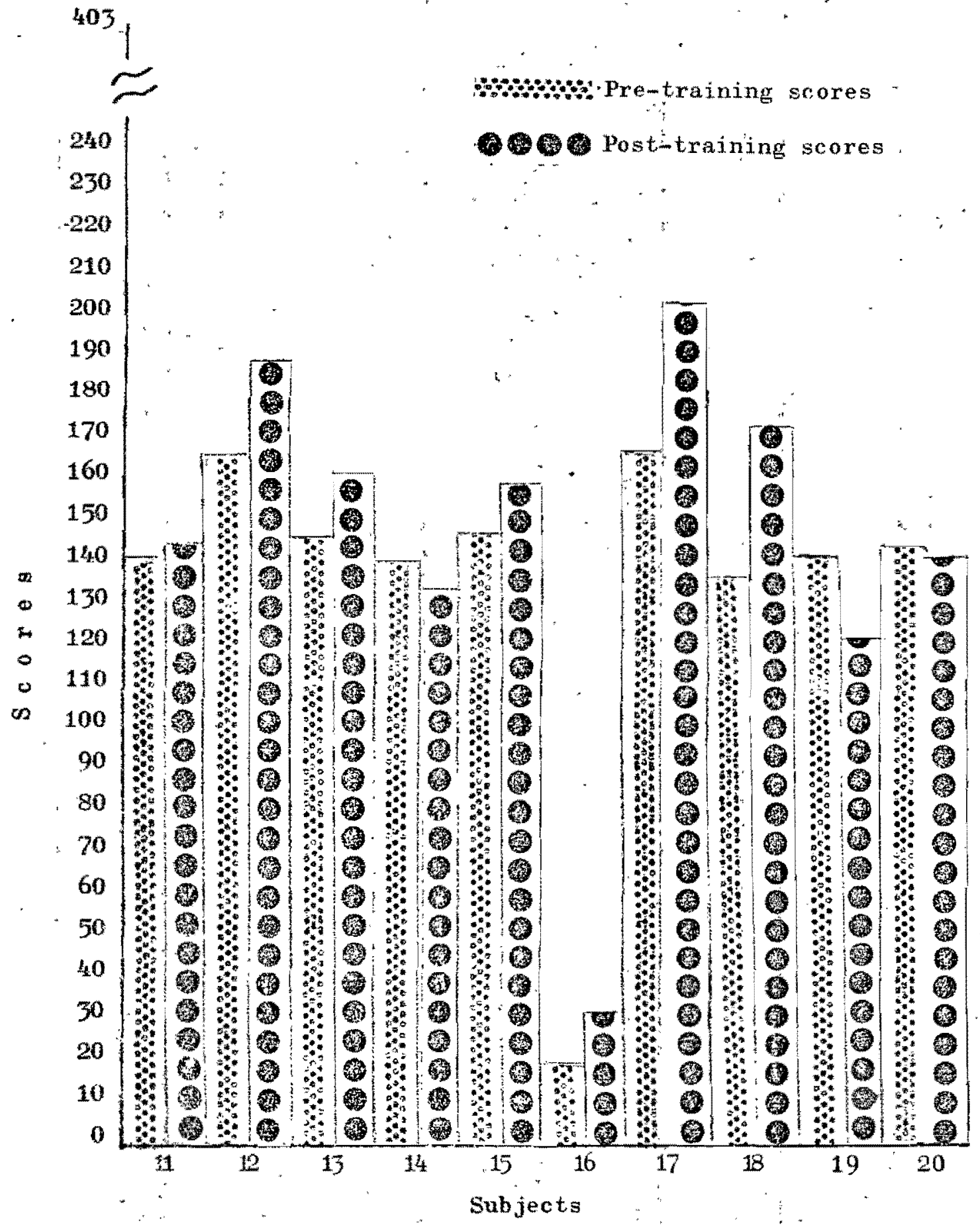

Figare 4. Seares for the cortrol group $(\mathrm{N}=10)$ for the pretrajingg and post-training administrations of the Primary I test. 
Table IV shows the results for the subjective attending behavior rating scale completed by the teachers of the population on three separate occasions: April 1, 1974; May 6, 1974; and June 6, 1974. Over- , all, the experimental group was rated higher subjectively by the teachers for demonstrated in-class attending behavior skills for the first and second ratings, but for the third rating the control group was rated higher. The initial discrepancy probably" reflects some error resulting from the random assignment. None of the three mean differences in ratings was statistically significant $(\mathrm{p}<.20, .10$, $.25)$.

\section{TABLE IV}

SURTECTIVE ATTENDTNG DFHAVIOR RATING, SCALE SHOWING MEAN SCORES, STANDARO DEVIATTONS, AND VARIAŃNCES

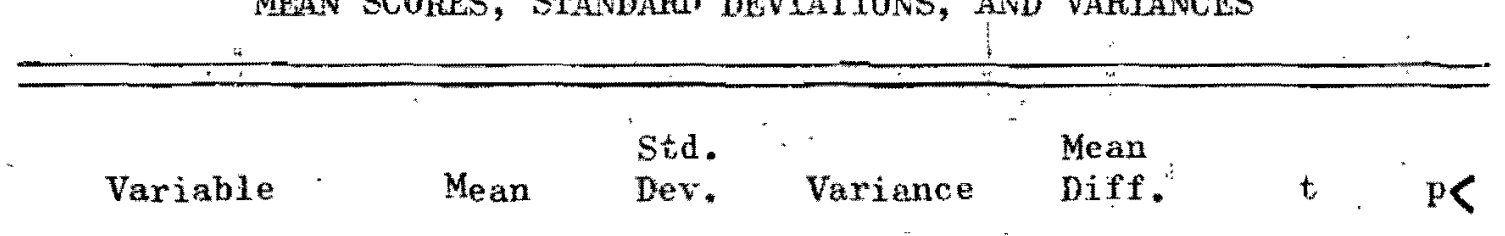

Lst Scale $4-1-74$

Experimental $\quad 28.50 \cdot 7.25 \quad 52.49$

Control $\quad 26.10 \quad 5.02 \quad 25.21 \div 2.40 \quad .86: \quad .20$

2nd Scale $5-6-74$

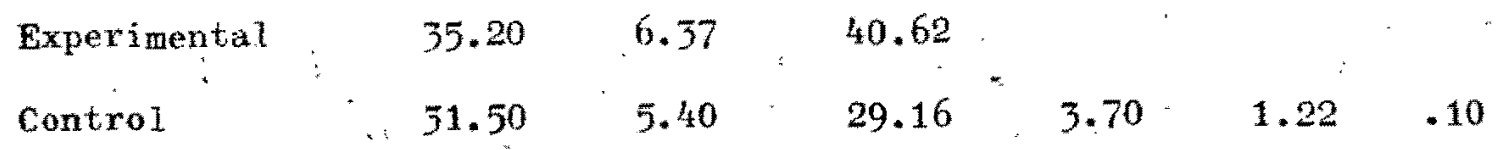

3 ra Scale $6-6-74$

Experimential

34.00

5.24

27.55

Control

36.20

8.91

79.51

2.20

.67

.25 
The mean scores for the subjective rating seales show that on the average the children improved over time when red by their teachers on in-class attending behavior. The control gxoup iwproved slightly more than the experimental group ( $t$ of 0.67 ), bat the difference could have occurred by chance with a probability greater than +40 . Table $V$ shows the correlation of the subjective ratings with post-Primer test scores. None of these correlations is statistically significant. Figures 5 and 6 graphically illustrate the scores for these rating scales. Numbers one through ten represent case numbers for the experimental group; numbers eleven through twenty represent case numbers for the control group.

\section{TABLE V}

COARELATION OF SUAJECTIVE RATINGS

WTTH POST-PRTMER TEST

Scones

$\begin{array}{ll}\text { First rating } & -.04 \\ \text { Second rating } & -.06 \\ \text { Third rating } & -.20\end{array}$


April 1, 1974, rating scale 00 May 6,1974 , rating scale

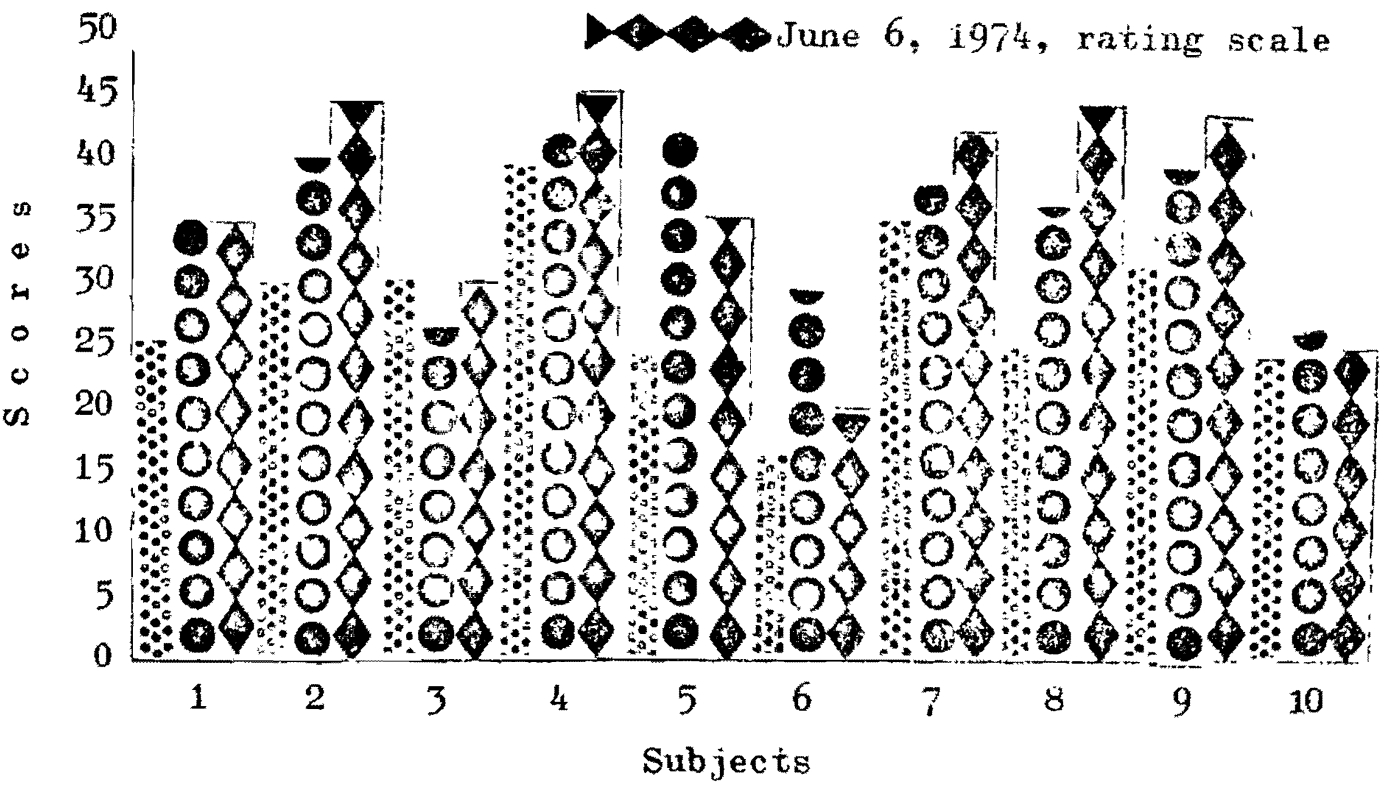

Figure 5. Scores for the experimenial group on three subjective rating scales.

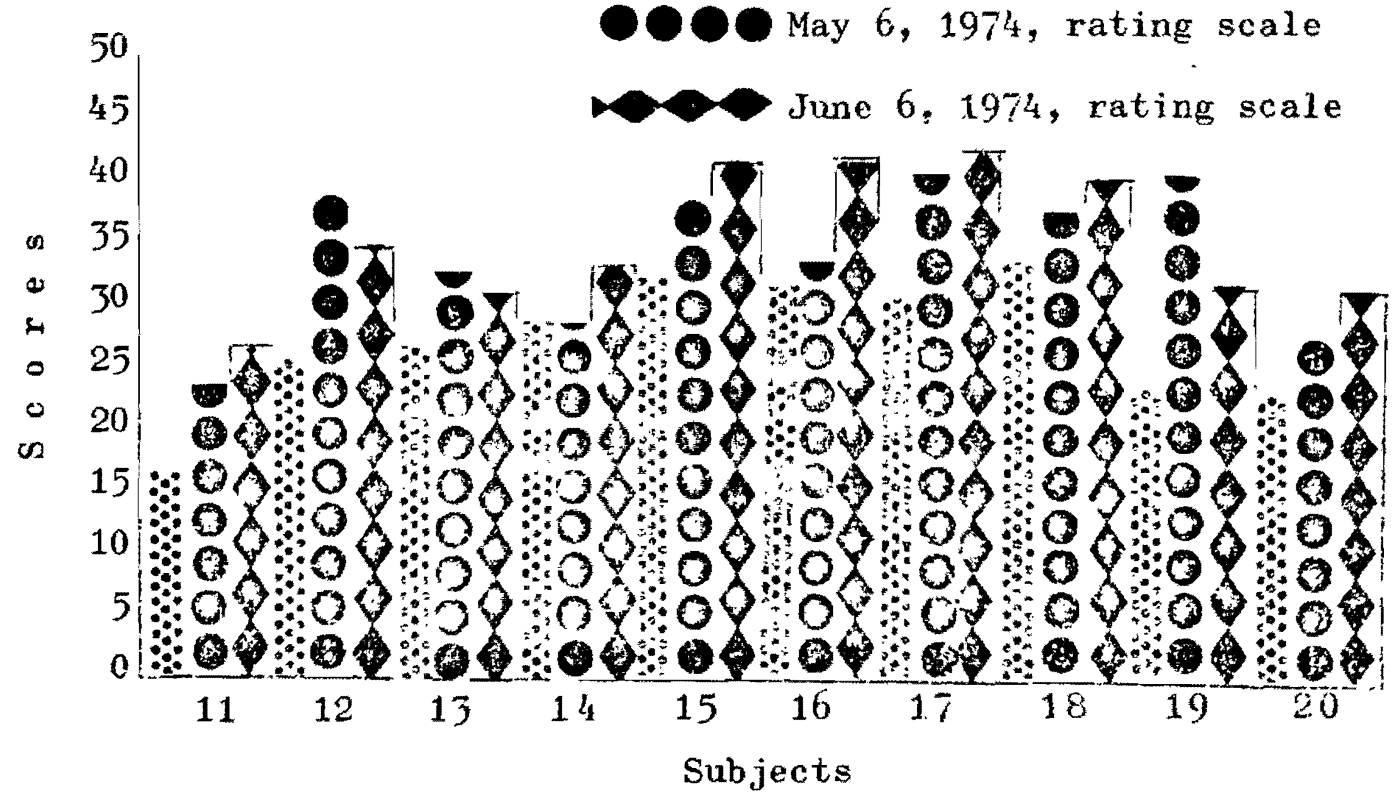

Figure 6. Scores for the control group on three subjective rating scales. 


\section{DISCUSSION}

The intention of this jnvestigation was to discover the effect of attending behavior training upon the academic performance of children as measured by a standard instrument.

Every child in the experimental group reached the terminal or stabilization stage of the Atterding Behavior preatment Program (see Appendix 1 ), me aning that within a program totalling two hundred minutes of treatment, including thirty minutes of baseline data gathering, each subject exhibited positive attending behavior involving sitting, listening, looking, and orientation to a task. These were children first desjgnated subjertively as "non-attenders" by their classroon teacher who was intinately familiar with their in-class behavicr after seven months of first grade, and second, met specific behavioral criteria aesigned by this researcher to describe a anonattending child.

The treatment program began with the clildren receiving continuous nutrient reinforcement ( $M \& M^{\prime} s$ ) for positive attending behaviors, and terminated with praise alone delivered on an intermittent "schedule to approximate more nearly a real-life classroom situation. In addition to the relatively lean reinforcement schedule at the end of the program, each child was exhibiting consistently positive attending behaviors wile faced with a combination of distractions, including: tape recordec noise, talk, and music; toys, games, candy, and other attractive stimuli on the table in front of him; and movement of this researcher alout the room as she delivered stimulus commands. 
The experimental group had significantly. higher" scores than the control. group" on the easiex post-Primer te:t; there was no significant difference between the two groups on the more difficult post-Primary I test. Thé data suggest, therefore, that non-attending children can be taught to tattend which vill allow them to improve on tasks involving knowledge which may already have been present, but which was not displayed beciase the-child did not attend to variables within the test situation such as directions and instructions. The more difficult test battery, however; would demand perhaps allonger time span between the end of the treatment phase and the post-test to allow the children a periodin which to practice and stabilize their newly-learned attending skills within the classroom learning situation or to acquire additional academic concepts by attending to instruction more effectively.

A secondary question was pursued: Will, participation in an individual treatment program have a positive effect on the subjective attitude of the teacher toward the child? There were no significant difference $s$ between the two groups with respect to the three subjective rating scales completed by each child's teacher. As a whole, the entire population improved in attending skills as subjectively judged by the teachers. This upward trend might be accounted for by maturation since the population did consist of first-grade children. Anotherfactor in the general uptrard trend might have been the "Hawthorne Effeet" (Cronbach, 1970), that is; the physical presence of this researcher and the fact that these non-attending children were involved in a treatment-based researcli project might have caused a change in 
their behavion unrelated to the nature of the formal training Also, the expectation of the teachers to view then more favorably with re. spect to in-class attending belavior as a result of selection for the ". experiaent may have biased the :teacher's ratiogs (Roschthal, 1963). The teachers may have felt that they were no longer alone in identifying these children as distracting and irritating and that positive steps were being taken to investigate this problem regardless of whether the child actualiy received attending behavior training or not.

The significant difference between the two groups on the Primer pre- andpost-tests was not reflected in the subjective rating scales, indicating that (1) possibly the rating scale was not sensitive enough to reflect subtle differences in attending behavior skills, and (2) subtle inter-child differences in in-class attending behavior were not apparent to the teachers, that is, teacher rating of in-class attending behavior does not necessarily" correlate positively with chis laren's performance on! a standardized test.

Previous research has examined attending behavior as it relates to several general aréas, such as learning acquisition, behavión modification, individual treatment programs, and the problem of pogitive carry-over.

The data from this research support specific findings within the general areas wentioned above. The fact that these shildren who were de icient in attending hehavior skills were also significantly behino in, at least one academic subject, such as reading or mathematics, enp- 


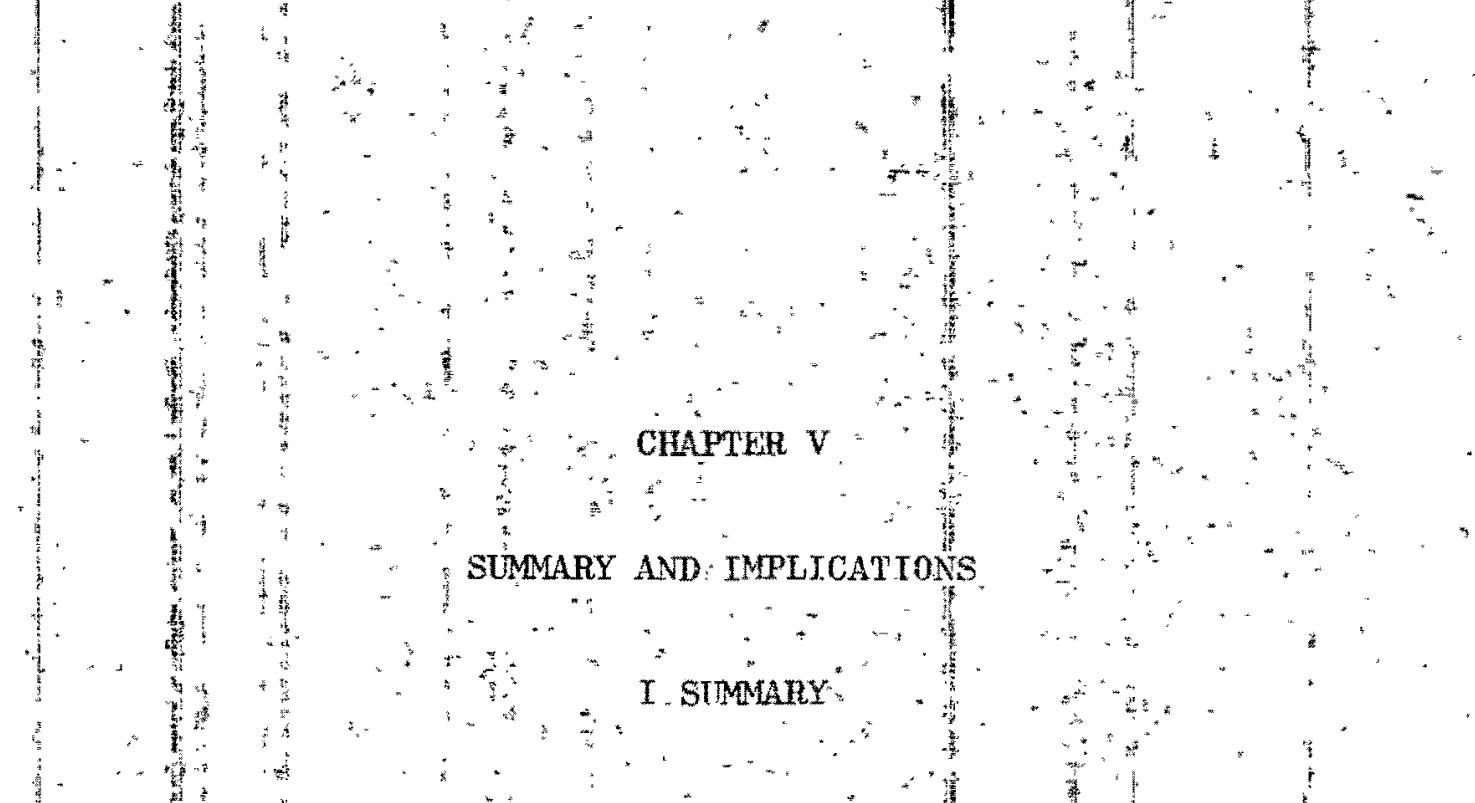

Various"studies have been implemented concerming the physiologicall and psychological components of attending behavior, particularly. in the area of the exceptional child. Little has bees done, however, to develop specific behavioral definitions of attending behavion and to incorporatê these into-treatwent-based research programs involving (.) normal children attending a regular public school.

The purpose of this investigation to discover if chidren The purpose of this investigation was to discover if children
from a regular public elementary school wo are deticient in attending behavior gkilis can be taught these skills, in a short-term behavior modification program and to determine it the gkills thus learned would facilitate leaming within the régular classroom setting. A secondary Pation question was asked: Will participation in an attending behavior treatment program change, the subjective attitude of the child to teach-

en in a positive direction?

The results demonstrated that attending behavior deficiencies in

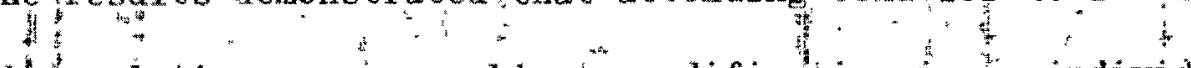
a normal population were amenable to modification în andividual treatmentprogram. This program terminated with a efor reinfoccenent schedule and dejiberate interjection of a nombination of distracting components into the situation. 
The experimental group had significantly higher:scores (t of -2.69) than the control group on the easier post-Primer test; there was no significant difference between the two groups on the more difficult post..primary I test. The data suggest, therefore, that nonattending children can be taught to attend which will allow then to improve on tasks involving knowledge which may already have been present, but which was not displayed because the child did not attend / to variables within the test situation such as directions and instructions. However, the more difficult test would demand perhaps a longer time span between the end of the treatment phase and the post-test to allow the children a period in which to practice and stabilize their newly-learned attending skills within the classroon learning situation or to acquire additional academic concepts by attending to irstraction more effectively.

There were no significant differences between the experimental and control groups on subjective rating scales completed on three different occasions by their teachers; in fact, the entire population showed an upward movement. This might be explained by maturation, by a change $i$ in the child's behavior unrelated to the formal treatment program or by a more favorable attitude of the teachers toward the children because an outside researcher had concurred in their evaluation of the children as non-attenders and that positive steps were being taken to modify their behavior regardless of whether the child actually received attending behavior trainingior not.

There was not a statistically significant correlation between any of the, three subjective rating scales and the post-Primer test 
scores indicating that (1) possibly the rating scale was not sensitive enough tọneflect subtle. differences in attending behạior skills, and (2) subtle inter-child differences in in-clas attending behavior were not apparent to the teachers, that is, teacker rating of in-class attending belatior does" not necessarily correlate positively with children's performance on a standardized test. "

. II IMPLICATIONS FOR CLINIC, CIASSROOM, AND FUTURE RESEARCH

Clinic

Since little learning can occur if the child does not attend (Kent, 1972) the clinician operating in an individual or small group situation mast be very sensitive to individua differénces between children ris respect to attending oehavior skills which are important prerequisites to learning. The clinician should utilize a shoxt time period tot track attending behavior of the child and pian appropriate treatment to modify demonstrable deficiencies. This does not imply that entire clinic sessions should be devoted to recording and modifying attending behavior; very short time periods (three to six minutes) can be extremely useful if work is done efficiently, and frequently.. Classroona

In the same manner the classroom teacher should be sensitive to attending behavior deficiencies exhibited by the children whose education is ber direct task and responsibility. This research indicates that systematic effort can inprove attending behavior skills even under conditions of minimal veinforcement and numerous diatractions. 
Therefore, the classroom teacher who does identify a clild as one who disrupts learning for himself or for others because he does not attend should provide some sort of treatment for him either through her own - efforts or by referring the child to special education or remedial persunnel.

In addition, teacher education should include some training in défining and treating attending behavior deficiencies. Existing programs, even on the graduate level, show a serious lack of such training in an area which is a crucial prerequisite to learning.

Research

Implications for future research stemming from this study are numerous, and controlled, systematic research is definitely needed. It is suggested that experimentation be done to determine a sufficiently long time span between the end of the treatment phase and the administration of the post-test to allow for optimal transfer and habituation of new skills.

Additionally, it is suggested that the treatment program be delivered within the regular classroom setting to overcome "carry-over" difficulties, thus eliminating differences between the setting in which the new skills were acquired and the setting in which they must be put to use.

A "blind" study would be useful to determine the effect on the subjective attitudes of the teachers toward the children if they were unaware which children actually received attending behavior training. In such 'study the researcher would take all the children out of the 
classroom, but half of them would play or tailk with the researcher and the other half would receive attending behavior training.

Hypothesizing from results of the subjective rating scale and research done by Rosenthal (1963) which suggests that experimenter expectations of performance are a powerful variable, it: seems logical that teachers be trained to modify attending 'behavior skills of the children ia their classroom. Thus, the child would have the increased benefit of the favorable attitude of the teacher who is delivering the actual program and tracking results. Such training might simply consist of showing the teacher the effects of poisitive reinforcement for good atteluding.

Research utilizing biofeedback techniques, such as galvanic slin response $(G S R)$, which reflects changes in resistance to the body's ovin electricity as it passes through the skin, wight support the exoiting hypothesis that the child could train himselif to attend by learning to control his own "internal milieu." Uno (1970) found that GSR is particularly sensitive to very small changes in the degree of awareness and that perception and memory improve when GSR signals that the organism is paying attention to a stimulus.

The field of attending behavior research is a fertile one for the experimenter desiring an area which is a crucial prerequisite to learning wut which has had few carefully controlled studies actually executied. 


\section{REFERENCES}

Bakan, $P$ (Ed.). Attention: An Enduring Problem in Psychology. Princeton: D. Van Nostrand Co., Inc. (1966).

Berlyne, D. E. Conflict, Arousal and Curiosity. New York: "McGrawHill (1960).

- Attention As a Problem in Behavioz Theory. In D. I. Mostofsky (Ed.), Attention: Contemporary Theory and Analysis: New York: Appleton-Century-Crofts (1970).

Birnbrauer, J. S., Bijou, S. W., and Wolf, M. Programmed Instruction in the Classroom. In L. P. Ullman and I. Kasner (Eds.), Case Studies in Behavioral Modification. New York: "Holt, Rinebart, and Winston (1965).

Broadbent, D. E. Perception and Communication. New York: Péryamon Préss (1958).

Craig, "H.; and Holland, A. Reinforcement of Visual Attending in Classrooms for Deaf Children. Journal, of Applied Behavior Analysis, 3, 97-109.(1970).

Cronbach, I. J. Essentials of Psychological Testing." New Kork: Harper \& Row $(1970)$.

Deutsch, J. A., and Deutsch, D. Attention, Some Theoretical Consideration. In P. Bakan (Ed.), Attention: An Enduring Problem in Bsychology. Princeton: D. Van Nostrand Co., Thc. (1966).

Duffy, E. Activation and Behavior. New York: Harper \& Row (1962).

Dulhaney, D. E. Hypotheses and Habits in Verbal Operant Conditioning. Journal of Abnomal and Social Psychology, 63, 251-63 (1961).

Eriksen, "C. W. (Ed.). Behavior and Awareness. Durham: Duke "Univexsity Press (1962).

Frostig, M., and Maslow, P. Leaming problems in the Classroom. New York: Grune \& Stratton, Inc. (1973).

Gardner, $I$. W. Some Eftects of Severe Disequilibrium on the Cognitive Functioning of the child. Acadenic Therapy, II; 4, 203-14 (Surmer, 1967). 
ports Kent:'s (1972) bypothesis that only minimal learning can occur if the child does not attend.

The treatment phase of this study utilized positive reinforcement and specific behavioral definitions which bear out Magdol's (1975) and Sloane and MacAulay's (1968) hypothesis that these are necessary components of a successful treatment program for attending behavior deficiencies. This, study also supports various research findings (Walker and Buckley; 1968; and Craig and Holland, 1970) that behavior modification techniques are effective in teaching positive attending behaviors.

This research also correlates with a study done by Walker and Buckley (1968) involving a bright, normal child who was taught at tending skills in an individual treatment program, and transfer of these skills to the classroom was obtained. 
Gordon, S. Sense and Nonsense About Brain-Injury and Learning Disabilities, Academic Therapy, 4, 251 (1970).

Hart, J., and Jones, B. Where's Hannah? New York: Hart, Inc. (1968).

Head, H. Aphasia and Kindred Disorders of Speech. New York: MacMillan $(1926)$.

Hebb, D. Drives and the CNS (Conceptual Nervous System). Psychological Review, 62, 243-54 (1955).

Hegrenes, J. R., Marshall, N. R., and Armas, J. A. Treatment As an Extension of Diagnostic Function: A Case Study. Journal of Speech and Hearing Disorders, 35, 182-87 (1970).

Hernandez-Peon, R. Physiological Mechanisms in Attention. In R. W. Russell (Ed.), Frontiers in Physiological Psychology. New York: Academic Press (1966).

Holland, J. G., and Schroeder, A. F. Teaching Machines: An Application of Principles from the Laboratory. Journal of Experimental Analysis of Behavior, 3, 275-87 (1960).

Horn, G. Physiological and Physical Aspects of Selective Perception. In D. L. Lehrman, R. Hinde, and E. Shaw (Eds.), Advances in the Study of Behavior. New York: Academic Press (1965).

Kent, L. R., Klein, D., Falk, A., and Guenther, H. A Language Acquisition Program for the Retarded. In J. E. McLean, D. E. Yodex, and R. L. Schiefelbusch (Eds.), Language Intervention with the Retarded. Baltimore: University Park Press (1972).

Lenneberg, E. The Natural History of Language. In F. Snith and G. Miller (Eds.), the Genesis of Language. Cambridge: MIT Press (1968).

Lovaas, 0. I., Berberich, T. P., Perloff, B. F., and Schaeffer, B. Acquisition of Imitative Speech in Schizophrenic Children. Science, 89-91 (February, 1966).

Lovejoy, E. Attention in Discrimination Learning. San Francisco: Holden-Day, Inc. (1968).

Lynn, R. Attention, Arousal and the 0rientation Reaction. 0xford: Pergamon Press (1966).

Mackintosh, N. J. Selective Attention in Animal Discrimination Learning. Psychology Bulletin, 64, 124-50 (1965).

Mackworth, J.F. Vigilance and Attention. Baltimore: Penguin Books, Inc. $(1970)$. 
Magdo1, M. Problems in Attention: Clearing Up the Terminology. Journal of Academic Therapy, 3, 141-53 (Winter, 1972-73).

Malmo, R. B. Anxiety and Behavioral Arousal. Psychological Review, $64,276-87(1957)$.

Marshall, N. R., and Hegrenes, J.R. Programmed Communication Therapy for Autistic Mentally Retarded Children. Journal of Speech and Hearing Disordexs, 35, 70-83 (1970).

- A Communication Therapy Model for Cognitively Disorganized Children. In J. E. McLean, D. E. Yoder, and R. L. Schiefelbusch (Eds.), Language Intervention with the Retarded. Baltimore: University Park Press (1972).

Martin, G. L., and Powers, R. B. Attention Span: An Operant Analysis. Exceptional Children, 33, 565-70 (1967).

McLearn, J. E., Yoder, D. E., and Schiefelbusch, R. L. Language Intervention with the Retarded. Baltimore: University Park Press (1972).

Menynk, P. The Acquisition and Development of. Language. Englewood Cliffs: Prentice-Hall, Inc. (1971).

Millikan, C., and Darley, F. (Eds.). Brain Mechanism Underlying Speech and Language. New York: Grune \& Stratton (1967).

Mondani, M. S., and Lutke, T. A. Relationship of Academic UnderAchievement to Incidental Learning. Journal of Consulting and Clinical Psychology, 33, 558-60 (1969).

Moray, N. Attention: Selective Processes in Vision and Hearing. London: Hutchinson, Ltd. (1969).

Mostofsky, D. I. (Ed.). Attention: Contemporary Theory and Analysi:s. New York: Appleton-Century-Crofts (1970).

Moyer, K. E., and von Haller, G. Attention Spans of Children for Experimentally Designed Toys. Journal of Genetic Psychology, $87,187-201$ (1955).

Penney, R. K. The Effect of Children's Orientation and Discrimination Learning. Journal of Experimental Psychology, 75, 140-42 (1967).

Redd, W. H. Attention Span and Generalization of Task-Related Stimulus Control: Effects of Reinforcement Contingencies. Journal of Experimental Child Psychology, 13, 527=39 (1972).

Reynolds, G. S. Attention in the Pigeon. Journal of Experimental Analysis of Behavior, 4, 423-27 (1961). 
Risley, T: and Wolf, M. Establishing Functional Speech in Echolalic Children. Behavior Research and Therapy; 5, 73-89 (1967).

Rosenthal,"R. The Effect of Experimental Bias on the Performance of the Albino Rat. Behavioral Science, 8, 183-89 (1963).

Ruble, D N. , and Nakamura, C. Y. Task 0rientation Versus Social Orientation in Young Children and Their Attention to Relevant Social Cues. Child Development, 42, 537-42 (1972).

Skinner, B. F. The Behavior of 0rganisms. New York: AppletonCentury-Crofts (1938).

Sloane, H., and Harper, L. J. Experimental Control During an Earthquake. Joumal of Experimental Analysis of Behavior, $8,425-26$ (1965).

Sloane, H., and MacAulay, B. Operant Procedures in Remedial Speech and Language Training. Boston: Houghton Mifflin Co. (1968).

Smith, F., and Miller, G. (Eds.). The Genesis of Language. Cambridge: MIT Press (1968).

Sprague, J. M. (Ed.). Progress in Physiological Psychology. Vol. I. New York: Academic Press (1966).

Staats, C. K., Schutz, R. E., and Wolf, M. The Condition of Testual Responses Using Extrinsic Reinforcers. Journal of Experimental Analysis of Behavior, $5,33-40$ (1962)...

Strauss, A., and Lehtinen, L. Psychopathology and Education of the Brain-Injured Child. Vol. I. New York: Grune and Stratton $(1947)$

Tichener, E. B. A Textbook of Psychology. New York: Macmillan $(1909)$.

Trabasso, T., and Bower, G. H. Attention in Learning: New York: Wilèy (1968).

Turnure, J. E. Children's Reactions to Distractors in a Learning Situation. Developmental Psychology, 2, 115-22'(1969).

- Reactions to Physical and Social Distractors by Moderately Retarded Institutionalized Children. Journal of Special Educatión, 4, 283-94 (1970).

Uno, $r$. The Effects of Awareness and Successive Inhibition on Interoceptive and Exteroceptive Conditioning of the Galvanic Skin Response. Psychophysiology, VII, 1, 27-43 (July, 1970) 
wagner

B. Maintenance of Discipline Through Increasing Children's Span of Attending by Means of a Token Economy. Psychology in the Schools, 8; 285-89 (1971).

Walker, H., and Buckley, N. The Use of Positive Reinforcement in Conditioning Attending Behavior. Journal of Applied Belavior Analysis, $1,245-50(1968)$.

White, S. H. Evidence for a Hierarchal Arrangement of Learning Processes. In C. Lipsitt and C. Spiker (Eds.), Advances in Child Development and Behavior. Vol. II. New York: Academic Press $(1965)$

Witte, K. L., and Grossinan, E. The Effects of Reward and Punishment Upon Children's Attention, Motivation, and Discrimination Learning. Child Development, 42, 537-42 (1971).

Worden, F. Attention and Auditory Electrophysiology. In E. Stel-

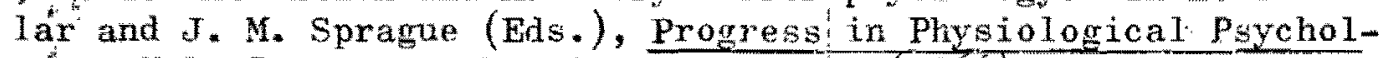
ogy. Vol. I. New York: Academic Press (1966).

Wyckoff, L. The Role of Observing Responses in Discrimination Learning. Psychological Review, 59, 431-42! (1952).

Zimmerman, E., and Zimmerman, J. The Alteration of Behavio: in a Special Classroom Situation. Journal of Experimental Analysis of Behavior, 5, 59-60 (1962). 


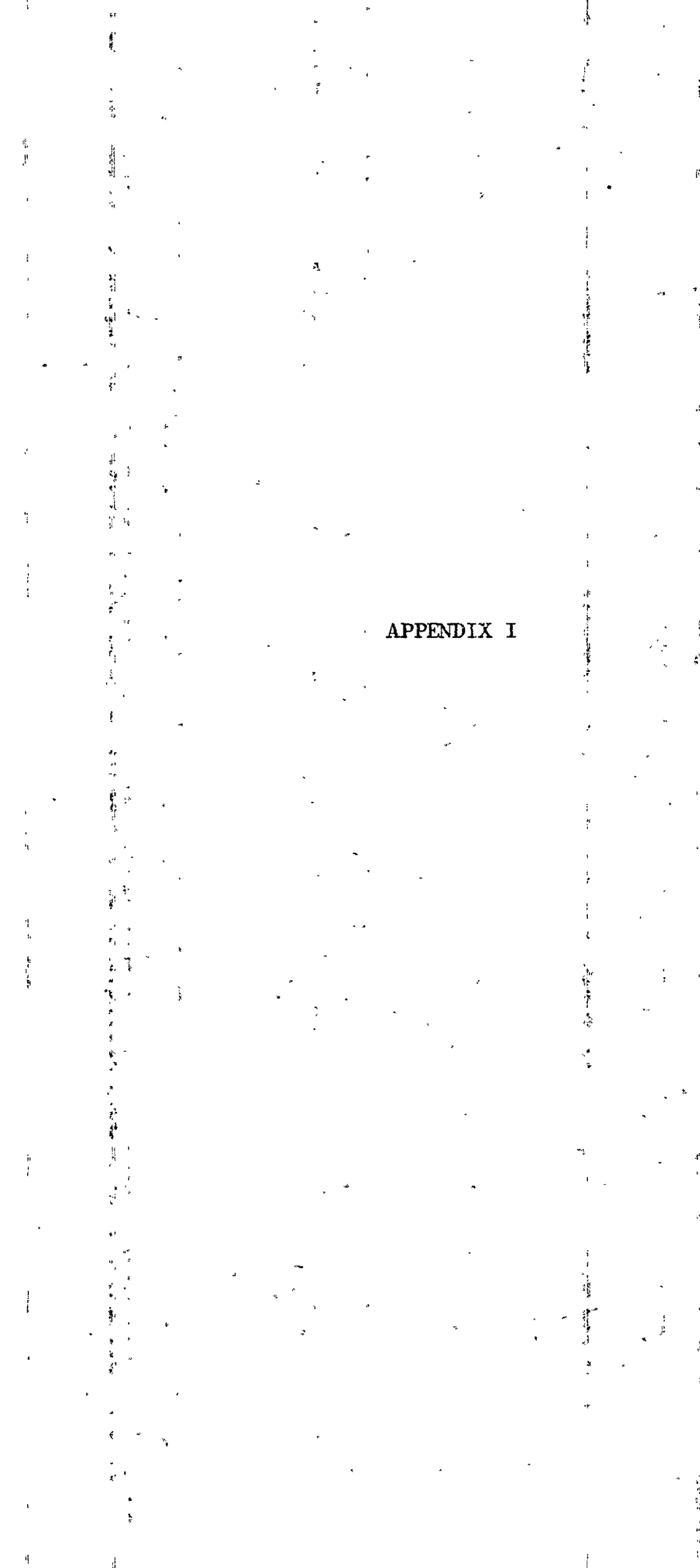


A HIERARCHAL BRANCHED TREATMENT PROGRAM

FOR MODIFYING ATTENDING BEHAVIOR

I THE PROGRAM MODEL:

Initiation of the Program.

obtain three baseline measures of sitting, looking, listening, and task-oriented behavior.

Stage $I$, Sitting Behavior

If. minus, branch to stage Ia.

Stage II, Visual Behavior

If. minus, branch to Stage IIa.

Stage III, Listening Behavior

If minus, branch to Stage IIIa.

Stage IV, Task-0riented Behavior

If, minus, branch to stage IVa.

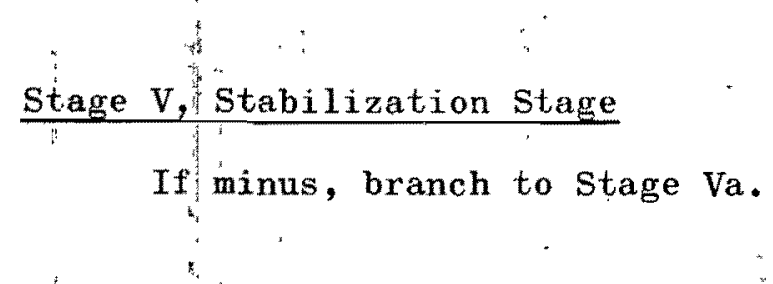

Termination of the Program 
II DELINEATION OF THE PROGRAM

Program Reinforcement

Begin each stage or branch with 100 per cent nutrient ( $M \& M^{\prime} s$ ) plus praise to reinforce. As long as child continues to respond positively, fade reinforcement as rapidly as possible to paper chips plus praise on an interval schedule, then to praise alone on an interval schedule. Terminal goal is a lean schedule of praise delivered once during a ten-minute treatment session. This'approximates reinforcement schedule. which child may receive in classroom or other instructional setting.

Stage I

Criterion. Child will sit in a chair for a ten-minute treatment. session, without extraneous fidgeting, squirming, foot-kicking, or shuffling; 90 per cent of time following command, " sit in this chair."

Stage Ia:

If response is negative, branching will be used. Branching consists of following steps:

Branch I. If child exhibits extraneous fidgeting, etc., clinician will physically intervene by placing her hand on appropriate extremity of child, saying, "Stop kicking," (or whatever incompatible motor behavior happens to be). When child complies, clinician will remove her hand and socially reinforce.

Branch II. If child does not sit long enough to meet criterion: A." Take child's hand. 
B. Lead him back to chair.

C. Repeat stimulus command.

D. Place your hands on his shoulders and push him gently into chair.

E. Remove your hands as soon as he sits in chair.

F.' Reinforce immediately with nutrient and praise.

G: Shape sitting behavior by delaying!delivery of reinforcement for increasingly longer intervals of time (suggested intervals are fifteen seconds, thirty seconds, one minute, two and one-half minutes, five minutes, ten minutes), and reinforcing child only for successively longer intervals of sitting.

H. Continue shaping process until child sits for ten minutes before being reinforced; then move child back into linear program.

\section{Stage II}

Criterion. Child will make direct eye contact "with clinician for ten seconds nine out of ten times when she says his name.

\section{Stage IIa}

If response is negative, branching will be used. Branching consists of following steps:

Branch I. If child does not make direct eye contact with clinician long enough to meet criterion, clinician will:

A.' Physically move child's head until it is in a direct line with her head, and keep her hands on side of his head.

B: Repeat stimulus.

C. As soon as child makes eye contact, drop her hands and rein- 
force with nutrient plus praise.

D. If he looks away before he meets criteria, say, "No, that's wrong. I want you to look at me."

E. Repeat steps A through C.

F. As soon as the period of correct responding (that is, sustained eye contact) reaches criterion, child will move back into linear program.

Stage III<smiles>[123IH]</smiles>

Criterion. Child will inhibit all extraneous vocalizations for ten seconds following command, "Listen," on nine of ten trials. Stage III'a

If response is negative, branching will be used. Branching consists of following steps:

Branch I. If child does not inhibit extraneous vocalizations long enough to meet criteria, clinician will

A. Drop her head and look down until child ceases vocalization. ment until it is met. i.

Branch II. If child still does not meet criteria after clinician completes Branch I, clinician will:

A. Place one finger over child's lips;to seal them; hold for five seconds; remove finger.

B. Reinforce with nutrient plus praise.

C. Repeat stimulus command. 
D. Reinforce approximations to criteria, delaying reinforcement until it. is met.

E. When it is met, move child back into linear prograin.

Stage IV,

Criterion. Child will follow directions regarding a task on nine of ten trials following a command.

Task: The specific task is left to clinician's discretion, keeping in mind that primary goal is for child to demonstrate he is attending: to task and not to exhibit a particular skill or concept which he may or may not possess. Example of a sample task: Clinician wi 11:

Stage IVa.

A. Place ten wooden blocks in front of child.

B. Say, "Watch what I do."

c. : Construct a pyramid with ten blocks.

D.I'Give child a corresponding set of blocks.

E. Say, "Now you make one just like the one I made."

If response is negative, branching will be used: Branching consists of following steps:

Branch I. Reduce number of blocks to simplify task.

Branch II. If response is still negative, clinician will:

A. Hold object next to her eyes saying, "Look at this."

B. Reinforce a correct response with praise.

C. Return object back to table in front of child saying, "Look at this." " 
D. Reinforce a correct response with praise.

E. Model task for, child.

F.: Repeat stimulus command.

G. If child attempts task, reinforce with nutrient plus praise.

H.: If child does not attempt task and exhibits competing behaviors, say, "No, that's wrong."

I. Repeat steps A through F.

J." If child does not exhibit competing behaviors, but does not attempt the task, be certain it is within his ability range and repeat steps C through $\mathrm{F}$.

K. As soon as child will follow directions regarding task nine of ten times upon command, child will move back into linear program. Stage V

Criterion. Child will demonstrate skills described in Stages I through IV 90 per cent of time following a command in'presence of competing stimuli. In order of addition to program, these are:

A. Extraneous objects on table in front of child (toys, objects, pictures, money, candy, etc.).

B. Extraneous tape-recorded noise (white noise, music, 'talking, buzzers, beeps).

C. Extraneous movement by clinician while giving stimulus commands (walking around room, standing up, and sitting down quickly). Stage Va

If any of competing stimuli results in negative response in any of the four parameters of attending behavior, branching will be used. 



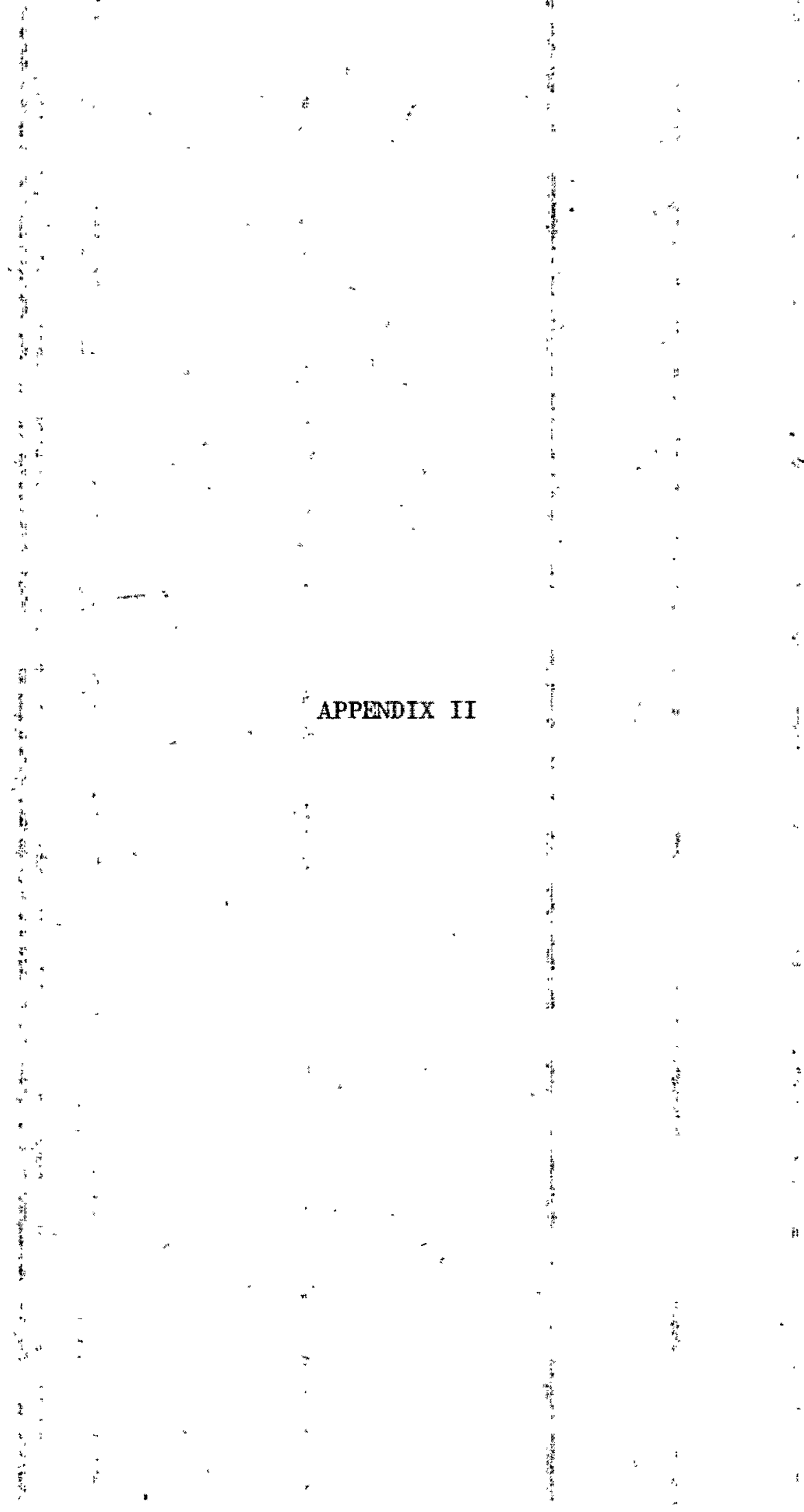


CLINICIAN:

SCHEDULE :

OBSERVER :

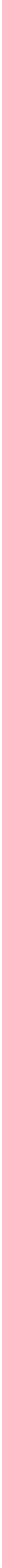



1. Can maintain sustained task-oriented behavior for an appropriate length of time.

2. Stays in his seat:during specified seatwork periods. $12: 345$

3. Remains quiet while you are giving group instruction 1 2: 3 4 5 (may include small group instruction as well as the Fentire class).

4. Remains quiet during rest periods, individual work periods, etc.

5. Follows simple verbal directions.

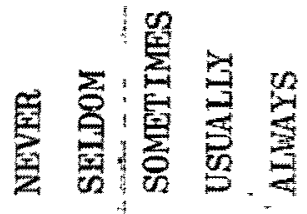

6. Looks" at you when "you talk to him individually."

7. Looks at you when you talk to him in a group.

8. Looks at an object if you direct him to do so. "Look at this book." "See this block." "Watch the red line.")

9. Refrains from physically distracting other children (touching them, grabbing objects from them, etc:) during rest periods or individual work periods.

10. Inhibits inappropriate physical movements/ while seated (excessive fidgeting, squirming; shufling, leg kicking, arm swinging, etc.).

11. I would rate this achild's present overallyattending

12,3 l 5

$1255 \quad 4 \quad 5$

i: $2: 5$ 4 5

1. $2: 345$ behavior as: 